\title{
Ultra Boost for Economy: Extending the Limits of Extreme Engine Downsizing
}

\author{
J.W.G. Turner, A. Popplewell, R. Patel, T.R. Johnson, N.J. Darnton, and S. Richardson \\ Jaguar Land Rover
}

\author{
S.W. Bredda \\ GE Precision Engineering \\ R.J. Tudor, C.I. Bithell, and R. Jackson \\ Lotus Engineering
S.M. Remmert and R.F. Cracknell
Shell Global Solutions (UK) \\ J.X. Fernandes \\ CD-adapco \\ A.G.J. Lewis, S. Akehurst, C.J. Brace, and C. Copeland \\ University of Bath \\ R. Martinez-Botas and A. Romagnoli \\ Imperial College London
}

\author{
A.A. Burluka \\ University of Leeds
}

\begin{abstract}
The paper discusses the concept, design and final results from the 'Ultra Boost for Economy' collaborative project, which was part-funded by the Technology Strategy Board, the UK's innovation agency. The project comprised industry- and academiawide expertise to demonstrate that it is possible to reduce engine capacity by $60 \%$ and still achieve the torque curve of a modern, large-capacity naturally-aspirated engine, while encompassing the attributes necessary to employ such a concept in premium vehicles.
\end{abstract}

In addition to achieving the torque curve of the Jaguar Land Rover naturally-aspirated 5.0 litre V8 engine (which included generating 25 bar BMEP at $1000 \mathrm{rpm}$ ), the main project target was to show that such a downsized engine could, in itself, provide a major proportion of a route towards a $35 \%$ reduction in vehicle tailpipe $\mathrm{CO}_{2}$ on the New European Drive Cycle, together with some vehicle-based modifications and the assumption of stop-start technology being used instead of hybridization. In order to do this vehicle modelling was employed to set part-load operating points representative of a target vehicle and to provide weighting factors for those points. The engine was sized by using the fuel consumption improvement targets and a series of specification steps designed to ensure that the required full-load performance and driveability could be achieved.

The engine was designed in parallel with 1-D modelling which helped to combine the various technology packages of the project, including the specification of an advanced charging system and the provision of the necessary variability in the valvetrain system. An advanced intake port was designed in order to ensure the necessary flow rate and the charge motion to provide fuel mixing and help suppress knock, and was subjected to a full transient CFD analysis. A new engine management system was provided which necessarily had to be capable of controlling many functions, including a supercharger engagement clutch and full bypass system, direct injection system, port-fuel injection system, separately-switchable cam profiles for the intake and exhaust valves and wide-range fast-acting camshaft phasing devices. 
Testing of the engine was split into two phases. The first usied a test bed Combustion Air Handling Unit to enable development of the combustion system without the complication of a new charging system being fitted to the engine. To set boundary conditions during this part of the programme, heavy reliance was placed on the 1-D simulation. The second phase tested the full engine.

The ramifications of realizing the engine design from a V8 basis in terms of residual friction versus the fuel consumption results achieved are also discussed. The final improvement in vehicle fuel economy is demonstrated using a proprietary fuel consumption code, and is presented for the New European Drive Cycle, the FTP-75 cycle and a $120 \mathrm{~km} / \mathrm{h}(75 \mathrm{mph})$ cruise condition.

CITATION: Turner, J., Popplewell, A., Patel, R., Johnson, T. et al., "Ultra Boost for Economy: Extending the Limits of Extreme Engine Downsizing," SAE Int. J. Engines 7(1):2014, doi:10.4271/2014-01-1185.

\section{INTRODUCTION}

In terms of light-duty passenger car fuel consumption, anything that can reduce light-load losses in the 4-stroke cycle engine is especially important on several of the common legislative drive cycles such as the New European Drive Cycle (NEDC) and proposed harmonized World Light-Duty Test Cycle (WLTC). Many routes have been and are being investigated with respect to reducing fuel consumption, most of which in the case of Otto (spark-ignition 4-stroke) engines target the reduction of throttling losses inherent in the cycle. Hybridization, homogeneous charge compression ignition, variable valve timing, exhaust gas recirculation and dilute combustion (including lean operation and with EGR) all provide benefits in this area to some degree, together with other effects. Of these, lean operation (either stratified or homogeneous) offers distinct thermodynamic advantages, but it presents challenges for exhaust after treatment (EAT). This is because of the associated emission of oxides of nitrogen carried in exhaust gas which contains excess oxygen. The EAT required is also very sensitive to fuel quality (specifically sulphur content), currently making it a regionspecific technology.

Of all the technologies recently investigated, engine 'downsizing' is especially beneficial in reducing throttling losses and thus has rapidly become a megatrend in the automotive industry. While primarily associated with spark-ignition (SI) engines, it also gives benefits in compression ignition $(\mathrm{Cl})$ engines where, while the throttling loss reduction may be absent, the improvement in mechanical efficiency that results from operating the engine at increased load is significant because of the increased friction that diesel engines carry versus their gasoline counterparts. As the present work will show, friction reduction (as well as reduced thermal losses) is a very important aspect of extreme downsizing.

The attractions to the OEM of gasoline engines include that their technology is very cost-effective to produce versus diesel engines (especially when the costs of the EAT system are included), that there are still significant efficiency gains to be made due to the losses associated with the four-stroke cycle
[1], and that pursuing the technology does not entail the writing-off of existing production facilities (as would be required by a quantum shift to electric or fuel-cell vehicles, for instance). As such, SI engine downsizing has become firmly established as the primary route for the automotive industry to improve vehicle fuel consumption, providing as it does an affordable solution to the twin issues of reducing tailpipe $\mathrm{CO}_{2}$ and improving fuel economy while also providing improved driveability from engines.

\section{Commercial View}

Most downsized gasoline engines offered to the market place at present appear to have a 'downsizing factor' of about $35-40 \%$. The downsizing factor is defined here to be

$$
D F=\frac{V_{\text {Swept }_{N A}}-V_{\text {Swept }_{\text {Downsized }}}}{V_{\text {Swept }_{N A}}}
$$

Eqn 1

where DF is the downsizing factor, $V_{\text {Swept }_{N A}}$ is the swept volume of a naturally-aspirated engine of a given power output and $V_{\text {Swept }_{\text {Downsized }}}$ is the swept volume of a similarly-powerful downsized alternative.

On a commercial level, it may be possible to eliminate entire engine familes from an OEM's range, for example by replacing 6-cylinder engines with 4-cylinder ones; the same could be said of 8- versus 6-cylinder configurations. Obviously, in the case of downsizing from a Vee-configuration engine to an in-line one, there are potentially significant further bill of materials (BOM) and manufacturing cost savings too. These savings can help to offset the additive technologies required to recover the power output from an engine which usually has a significantly smaller swept volume, because clearly some means of increasing specific output has to be found to retain installed power in a vehicle. 
Operation on the 2-stroke cycle would bring all of the above benefits and more, but is not currently favoured by the industry because of the amount of investment historically made in the production of poppet valve 4-stroke engines. This has not stopped some researchers from investigating this operating cycle again, even proposing a 2-stroke/4-stroke switching approach with a poppet valve architecture suitable for manufacture down existing transfer lines [2] , but until a practical means of instantly and safely changing camshaft speed by a factor of two is created, it is difficult to see such a concept progress to production.

As a consequence, the most pragmatic approach taken to date has been to pressure charge the 4-stroke engine, normally by turbocharging it, thus recovering some of the waste thermal energy in the exhaust. A key enabler for this approach was the development and application of gasoline direct-injection (DI) systems, which allowed the use of the latent heat of vaporization of the fuel to be beneficially employed to allow an increase in compression ratio (CR). A further development was the adoption of camshaft phasing devices which, together with the DI system's ability to delay fuel introduction until after exhaust valve closing (EVC), permitted large amounts of valve overlap to be used without combusting short-circuited fuel in the exhaust path. In turn this permitted large amounts of scavenging air to be passed through the combustion chamber, simultaneously shifting the operating point of the turbocharger compressor (to the benefit of driveability) and internally cooling the chamber (to the benefit of flushing out residual gases and trapped charge temperature reduction, both extending the knock limit of the engine) []ㅡ. Under some conditions secondary oxidation of partially-combusted exhaust products in the exhaust could also potentially safely increase the enthalpy available to the turbine and reduce chemical energy losses. These approaches potentially allow further increases in CR for the turbocharged DI spark-ignition engine (DISI) or a higher DF to be used, again to the benefit of part-load fuel economy.

Various supporting technologies have been developed and productionized such as the adoption of pulse-divided exhaust manifolds in 4- and even 8-cylinder engines $[4,5]$, the use of integrated exhaust manifolds []], combinations of the two []], or adoption of 3-cylinder groups with or without some of the other features $[\underline{8}, \underline{9}]$. Furthermore, combined super- and turbocharging systems have also been in production for some time, allowing positive pressure to be applied to the intake all the time and desensitizing the engine to the pulse overlap effects (particularly an issue in four or more cylinder groups) [10]. Other interesting downsizing approaches such as Divided Exhaust Period or Valve-Event Modulated Boost hold promise in improving the efficiency of the Otto cycle through pumping work reduction, scavenging and related combustion improvement $[\underline{11}, \underline{12}, \underline{13}]$.
One early successful downsized engine with a DF of approximately $40 \%$ provided a reduction in fuel consumption on the New European Drive Cycle of $20 \%[14]^{1}$. A single research engine has been shown with a DF of $50 \%$ [16]. The authors believe that no engines have been developed with a higher DF. Consequently the collaborative project 'Ultra Boost for Economy' (or 'Ultraboost') was formed with the major tasks of specifying, designing, building and operating an engine with a minimum of $60 \%$ downsizing factor, this being defined by the torque curve of an existing high-feature, high-performance naturally-aspirated engine. Through the results obtained it was intended to establish what the limiting factor to downsizing at this level was and whether there would be further benefits in downsizing further. The paper outlines how this was achieved.

\section{BACKGROUND TO THE PROJECT}

\section{Project Targets}

As mentioned, the project was to demonstrate the feasibility of $35 \%$ reduction in fuel consumption through extreme downsizing. Specifically, this was to be relative to a 2010 model year (MY) Range Rover fitted with the Jaguar Land Rover (JLR) AJ133 naturally-aspirated (NA) V8, which was a current production vehicle when the project was started. The developed concept was to be modelled in a 2013 MY Range Rover. Although hybridization is not a feature of the change in vehicle specification, because of the technical changes made to the vehicle line since, stop-start, vehicle mass reduction and the adoption of a transmission with a greater number of ratios were included as assumed technology upgrades. The effects of these will be discussed in further detail later in this paper.

From the outset, and in order to have a robust baseline for comparison, the general project target of achieving the same torque curve of the naturally-aspirated (NA) version of the 5.0 litre Jaguar Land Rover AJ133 V8 engine was adopted. Although transmission matching can disguise the typically reduced low-speed torque of downsized engines when they are used in passenger cars, high torque at low engine speeds is still a significant advantage for off-road driving and so it was considered desirable to retain this attribute for this research project. Furthermore, driveability comparable with the JLR V6 diesel engine was to be provided for the same reason. From previous studies [15], a DF of $60 \%$ would be expected to yield $23 \%$ of the $35 \%$ improvement required, with stop-start functionality coupled to the other vehicle changes being expected to supply the other $12 \%$. Thus an outline specification of a 2.0 litre pressure-charged DISI engine was created as a first iteration at the outset to the project.

\footnotetext{
1. Note that this result is not independent of vehicle effects: a six-speed gearbox was also adopted with the 1.4 litre Twincharger engine to help provide the reduction in fuel consumption. From work previously conducted by JLR [15], a DF of $40 \%$ would in itself be expected to yield a fuel economy improvement of about $12 \%$ of the reported $20 \%$. Note that the $12 \%$ value is considered to be only due to downsizing the engine swept volume and the friction reduction due to down-cylindering, and does not include vehicle and transmission modifications taking the total to $20 \%$.
} 
Figure 1 shows that adopting this swept volume would require operation at up to 32.4 bar brake mean effective pressure (BMEP). Consideration of a realistic mean peak cylinder pressure (PCP) in the region of 130-135 bar was also included in the engine sizing decision. Figure 1 also illustrates one extremely challenging target for the project in matching the torque curve of the original 5.0 litre V8 NA engine: the new 2.0 litre engine has to produce 25.1 bar BMEP at $1000 \mathrm{rpm}$, where preignition and other abnormal combustion phenomena would normally be expected to be severe limitations. Taken together, these targets were considered extremely aggressive and beyond anything achieved up to that point in time.

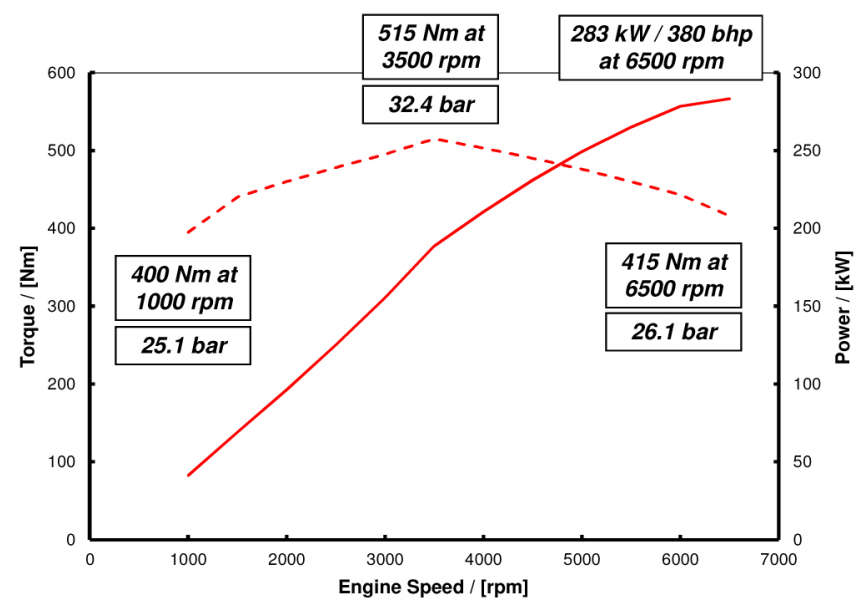

Fig. 1. Target power and torque curves and selected associated BMEPs for a 2.0 litre engine

\section{Project Partners}

Ultraboost was a collaborative project part-funded by the Technology Strategy Board, the UK's innovation agency. The project partners were Jaguar Land Rover, Lotus Engineering, GE Precision Engineering, CD-adapco, Shell Global Solutions (UK), the University of Bath, Imperial College London and the University of Leeds. It started in September 2010 and had a duration of three years.

The structure of the project has been described in detail elsewhere in an earlier publication [17]. Nevertheless, it is useful to recap the members and their responsibilities before discussing its phases.

Jaguar Land Rover (JLR) was the lead partner, with responsibility for engine build, general procurement, enginemounted charging system integration and overall project management.

GE Precision Engineering provided engine design and machining capabilities as well as background knowledge on the design of high-specific-output racing engines.

Lotus Engineering provided dedicated engine management systems (EMS), 1-D modelling and know-how on pressurecharged engines, and support for engine testing.
CD-adapco supported the design process with steady-state and transient CFD analysis primarily in order to support intake port design.

Shell Global Solutions provided knowledge of autoignition phenomena, base fuel for engine development (including full fuel analysis), detailed lubricant analysis to aid in interpretation of engine wear, and designed and interpreted a test matrix of fuel formulations in a thorough programme to screen engine response to various fuel properties, results of which will be reported elsewhere (see later).

The University of Bath conducted all of the testing, having dedicated boosting and cooled exhaust gas recirculation (EGR) rigs which were used for the initial Phase 2 testing of the demonstrator engine (see below).

Imperial College London specified the charging system components, with support from both JLR and Lotus, and tested them in order to characterize them accurately so that the 1-D model was as robust as possible.

The University of Leeds developed their autoignition model to assist with the 1-D modelling process.

\section{Phases of the Ultraboost Project}

The project was split into several parts, which are shown schematically in Figure 2. This has been discussed in detail elsewhere but is reprised here in order to provide context when discussing the engine results later in the paper.

In Phase 1, a production AJ133 NA engine was commissioned on the test bed at the University of Bath using the Denso EMS which was then used in production. This part of the programme provided baseline data for the V8 engine in terms of performance, fuel economy and transient response, while also facilitating the shaking down of the test facility at Bath.
PHASE 1 $2010 \Rightarrow 2011$

PHASE 2 $2011 \Rightarrow 2012$

PHASE 3 $2012 \Rightarrow 2013$

\section{AJ133 V8 NA}

Capacity: 5.0 litre

Bore: $92.5 \mathrm{~mm}$ Stroke: $93 \mathrm{~mm}$

Baseline with Denso EMS, then repeat with Lotus EMS

Capacity: 2.0 litre

Bore: $83 \mathrm{~mm}$ Stroke: $92 \mathrm{~mm}$

New combustion system

New head, crank, conrod, piston, intake

and exhaust systems

Boosted by facilitated charging

Technology: PFI \& DI, EGR, CPS Lotus EMS

UB200: AJ133-based mule

As UB100 but with engine-driven boosting and EGR systems

\section{UB100: AJ133-based mule}

Fig. 2. The three phases of the Ultraboost project 
The Denso EMS was then replaced by the Lotus system, which was shown to be capable of controlling the engine and giving exactly the same performance at full and part load, including matching the steady-state fuel consumption of the production engine and Denso EMS combination to an average of $0.6 \%$ lower (see later). This phase therefore set the fuel consumption benchmarks for the project's downsized engine design and proved the capability of the Lotus EMS when controlling a direct injection engine with twin electrohydraulic cam phasers and two high-pressure fuel pumps, while at the same time utilizing multiple-injection and multiple-ignition strategies.

In parallel with the V8 engine test work, during Phase 1 the first iteration of Ultraboost engine was specified, designed and procured. This was to be known as UB100. In order to do this, the pooled knowledge of all the parties was used, resulting in a current industry best-practice high-BMEP engine with some additional novel features. It was first tested in Phase 2, the test programme of which utilized a test bed combustion air handling unit (CAHU) and a specially-designed EGR supply rig. Phase 2 was primarily intended to prove out the efficacy (or otherwise) of the newly-developed combustion system. The testing portion of this phase would also permit fuel testing to be undertaken without the complicating effects of an engine-driven charging system, although this important subsystem would also be specified, modelled, procured and validated in a parallel work stream within Phase 2.

Because the UB100 engine would not have a self-driven charging system, in order to provide relevant results throughout testing this engine it was operated with boundary conditions determined by the detailed 1-D model (itself used to help the design process and the specification of the charging system to be used later). Thus, in areas where the supercharger would have to operate, any supercharger drive torque which the engine would ordinarily have to supply would be part of the necessary target torque for the Phase 2 engine to produce at the flywheel, i.e. the brake torque would have to be greater than the values shown in Figure 1 by a previously-determined amount. Where the turbocharger would be operating by itself, just the pressure and temperature boundary conditions would be sufficient to establish whether the engine was capable of meeting the targets with the eventual engine-mounted charging system in place. As reported later in this paper, the turbocharger (but not the supercharger) would in fact be tested on the UB100 engine in the latter stages of Phase 2, to allow engine-based verification of the turbocharger run-up line as input to the choice of supercharger drive ratio for the Phase 3 engine.

Phase 3 was intended to comprise any necessary redesign of the UB100 engine coupled with mounting the engine-driven charging system. The engine was then to be known as UB200.

Ultimately, the level of achievement of the project targets was to be demonstrated by a combination of direct measurement of engine performance on the dynamometer (power, torque, fuel consumption etc.) and modelling (by the application of gathered minimap fuel consumption data to a proprietary vehicle performance modelling tool).

\section{ULTRABOOST ENGINE DESIGN}

\section{Major Technologies Employed on the Core UB100 Engine}

In order to save time, the Phase 1 engine was designed using the cylinder block and main bearings of the donor Jaguar Land Rover V8 engine, with Bank B (the left hand bank) blanked off. This approach has been discussed in a previous publication [17], and was chosen since the general engine structure and main bearings were already known to be capable of handling the stresses imposed by the power and torque targets; essentially, these components are used in the supercharged version of the AJ133 engine which has much higher ratings than the NA variant [18].

A flat-plane crankshaft was used, which also reduced the engine stroke, while a siamesed liner pack was employed to reduce the bore diameter. The UB100 engine also used the standard water, oil and high pressure fuel pumps, main bearing shells and fuel rails of the AJ133, plus other parts as suited to the task. For general design information on the donor AJ133 engine, including its use of a sump-mounted auxiliary shaft to drive the fuel pumps (rather than using the camshafts), see [18].

In order to minimize flame travel while at the same time providing sufficiently large throat diameters for gas exchange, the 1-D model was used to determine the minimum practical bore size. This was established to be $83 \mathrm{~mm}$, which, with a stroke of $92 \mathrm{~mm}$, gave a swept volume of $1991 \mathrm{cc}$. The compression ratio was set at 9.0:1 with a substantially flattopped piston. A study of the possible combustion chamber geometries led to an included valve angle of $45^{\circ}$, giving an open chamber for minimum quenching and heat loss (returned to later in the Discussion). Bulk air motion and turbulence was to be provided by a new design of intake port, the performance of which is detailed later.

The only compromise associated with adopting the approach of using the AJ133 cylinder block was that the cylinder head bolt spacing would have to be the same as that of the donor V8, which has a much bigger bore of $92.5 \mathrm{~mm}$ and an associated cylinder centre distance of $100 \mathrm{~mm}$ [18]. A completely new cylinder head was designed with these criteria in mind which incorporated a second-generation close-spaced DI combustion system, cam profile switching (CPS) on both the inlet and exhaust cams and the new inlet ports. CFD was used to verify the cooling capability of the existing block water jacket, liner pack and head; as a result deflector plates were added to the cylinder block jacket in order to provide robust cooling of the structure. 
The incorporation of CPS tappets on the inlet side was in order to allow investigation of a degree of Miller-cycle operation at both low- and mid-load, as already used in the naturallyaspirated AJ133. Their use on the exhaust side was in order to minimize exhaust pulse interaction at low engine speeds, which is an issue for linked cylinder groups comprising more than three cylinders operating with conventional exhaust periods, as is the case here $[\underline{3}, \underline{19}]$. The $1-D$ model was developed in concert with this design process, and was used to help guide it since it was also being used to help specify the charging system, thus assisting in the important choice between a turbocharger or supercharger for the high-pressure stage of the compound charging system arrangement $[17,20]$.

The cylinder head also adopted the dual continuously-variable camshaft phasing (DCVCP) devices of the AJ133; its chain drive system, albeit slightly modified, was also carried over. The DCVCP system necessitated the addition of 'thumper cams' at the rear of the head in order to provide an uneven torque input to drive the fast-acting phasers to move the camshafts. This thumper cam system comprised a follower with a spring and twin cam lobes on the shaft, minimizing parasitic losses, but nevertheless they would have slightly increased the friction of the engine, a subject which will be returned to in a later section.

\section{A photograph of the assembled cylinder head with tri-lobe} camshafts for the CPS tappets in situ is shown in Figure 3. The two-lobe thumper cams can be seen at the back of the head.

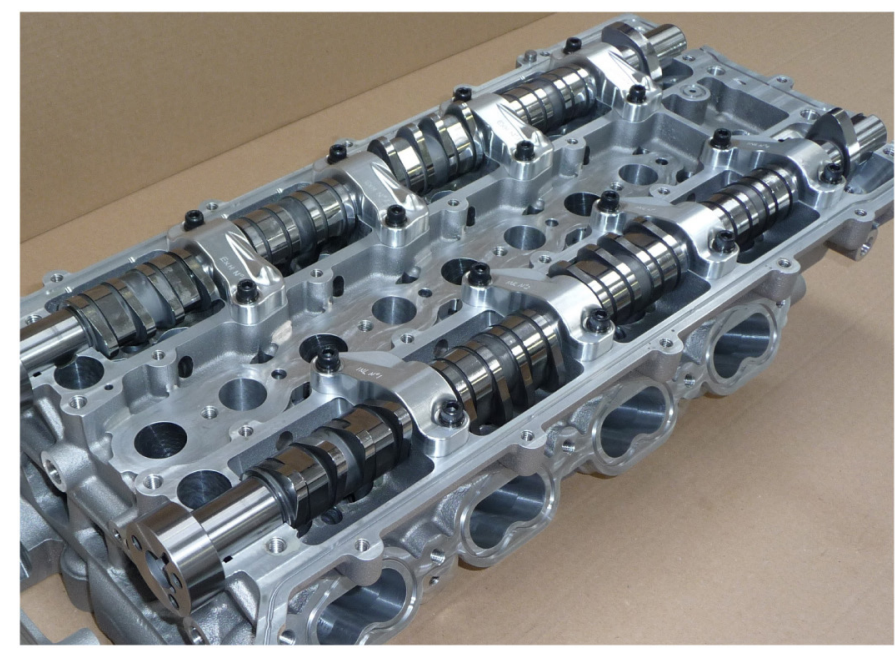

Fig. 3. Cylinder head assembly. Note the fully-machined inlet ports and the twin-lobe 'thumper cams' at the back of the head, providing uneven drive torque for the fast-acting camshaft phasing devices

Another feature of the combustion chamber and cylinder head configuration was the potential to fit a second spark plug under the intake ports. This was facilitated by two things: first, the fact that in order to achieve high tumble rates DISI engine ports have generally become 'raised' above their port-fuel injection (PFI) predecessors, and second, the adoption of central DI meant that the injector was not located under the inlet ports. The ability to put a second ignition point under the intake valves, where knock can frequently occur, was considered to be advantageous but was unfortunately not tested within the project due to time constraints.

Simple log inlet and exhaust manifolds were designed for the initial testing of the UB100 engine. An exhaust back pressure (EBP) valve was used to set the requisite manifold pressure to mimic pre-turbine conditions in the engine as determined by the 1-D model.

\section{Specific Design Details of the Core UB100 Engine}

The core UB100 engine, which was also the basis of the later UB200 build, was designed using a holistic design approach. Attention to detail was of particular importance given the operating conditions and the thermal loading that such a highly-boosted engine would be subjected to. Each system, sub-system and component was critiqued and where necessary optimized with respect to its form, fit and function: no unnecessary risks were taken, safety factors were kept sensible and reliability was of key importance. Initial 1-D cylinder pressure data was deemed pessimistic as combustion system performance was anticipated to be more favourable, and hence the stress analysis boundary conditions applied were based on higher loads which, given the eventual reliability of the engine, proved prudent. Component fatigue life constraint was based on 32 million cycles using measured S-N data. Further details of some specific components are reported below.

\section{Cranktrain}

The piston was made from heat-treated Al 2618A aluminium alloy and designed to mitigate potential knock or pre-ignition while being optimized for performance: mass, component life, friction, oil carry-over, blow-by and manufacture. The ring pack was also specified to minimize oil carry-over, friction and top ring groove wear. The gudgeon pin was made from GKHW heat-treated steel, and was nitrided and DLC-coated to prevent galling.

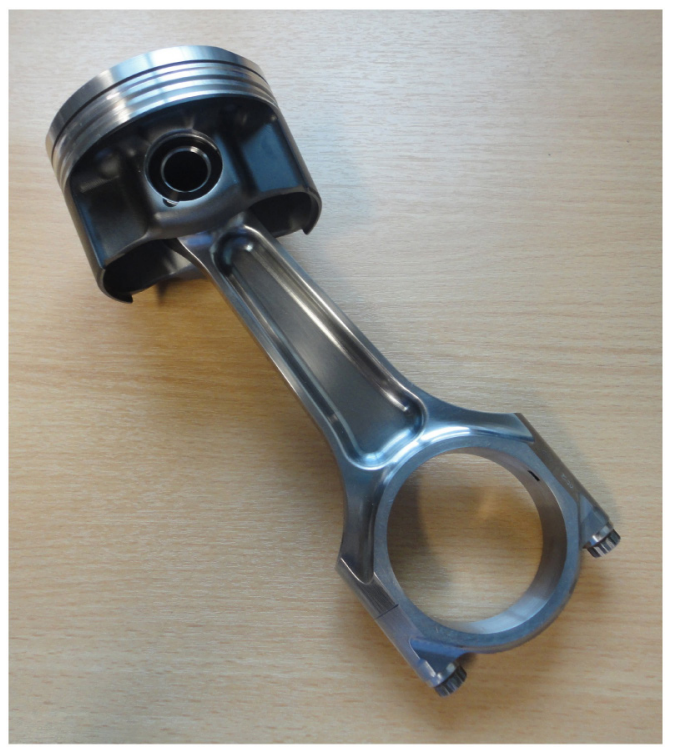

Fig. 4. Piston and connecting rod assembly 
The connecting rod was $300 \mathrm{M}$ heat-treated steel with a steel bush and used MJ8 high tensile bolts. The rods turned a GKHW heat-treated steel crankshaft which was also nitrided.

A photograph of the piston and connecting rod assembly is shown in Figure 4.

\section{Crankcase and Liner Pack}

The crankcase was an aluminium pressure die casting (from the AJ133 V8 donor engine). The open-deck arrangement was modified to receive a single-piece liner pack and seal arrangement. O-ring tracks were machined for fluid sealing within the block, as discernible in Figure 5 . The liner pack itself was a single-piece design optimized for cooling and stiffness and made from Al 2618A heat-treated billet. Nickel-ceramic bore coating was applied. Twin grooves for O-ring seals were machined into the lower portions of the protruding liners which were then spigotted into the block. Figure 6 shows a photograph of the liner pack, in which the O-ring grooves at the bottom can just be discerned.

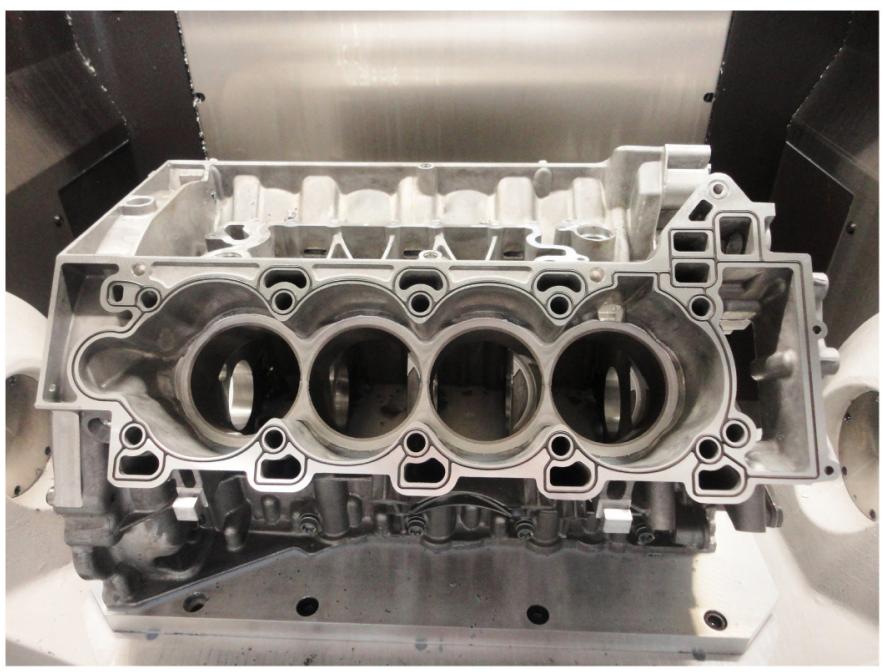

Fig. 5. Modified crankcase (A Bank only). Note O-ring grooves for fluid sealing

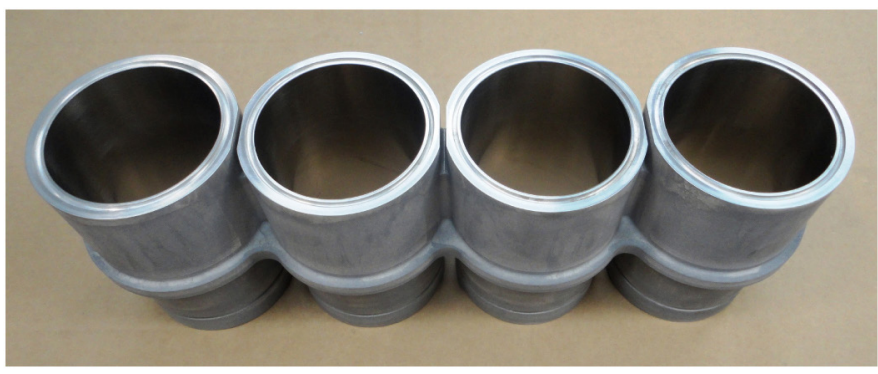

Fig. 6. Liner pack

Instead of a conventional cylinder head gasket, gas-energized rings (or "Wills rings") were used for combustion sealing. The groove for these can be seen on each cylinder in Figure 6.

\section{Cylinder Head Assembly}

The cylinder head was made from an Al A356 heat-treated sand casting. The combustion chamber, inlet and exhaust ports were designed to promote advantageous in-cylinder charge motion and flame propagation; the intake port is discussed in detail later. The ports and combustion chamber were fully machined.

The DI injector and spark plugs were packaged in a similar 'asymmetric' arrangement to AJ133 [18], and the coolant jacket was optimized to achieve target heat transfer coefficients (HTCs) with minimal pressure drop.

Camshafts, including the thumper cam arrangement for the cam phasers, and the CPS tappet system were also packaged into the head. The inlet valves were stainless steel and the exhaust valves were sodium-filled and made from Ni80A steel. The valve guide and seat material was chosen based on wear and heat transfer properties. The cam cover was a structural design with integral front and rear cam caps.

\section{Water-Cooled Exhaust Manifold}

Initially, a tubular steel manifold was used, but it was decided to design and procure a water-cooled exhaust manifold (WCEM) for reasons which will be discussed later. This was tested during part of Phase 2 and throughout Phase 3. It was an Al A356 heat treated sand casting. The manifold was pulse-divided and designed to help achieve sufficient cooling for turbocharger protection. This component will be discussed in greater detail later in the section related to UB200 design.

\section{Intake Port Design and Performance}

In order to achieve the necessary air motion and mixture preparation in DISI engines there has been a general evolution towards high-tumble intake ports; this has only been made possible by the simultaneous adoption of pressure charging to overcome the flow loss generally associated with this move. It is worth noting that under-port placement of the injector has had a symbiotic relationship with the developmental direction of the general port configuration of DISI engines, but nevertheless the situation has arisen that reduced flow rate is seen as a worthwhile trade-off to achieve high tumble rates (and hence improved mixture preparation and charge cooling). Obviously, any loss of flow capability can be expected to manifest itself in increased charge cycle (pumping) work, and so a desire for Ultraboost was to achieve a balance of flow and tumble considered to be significantly beyond the current state of the art. This was especially important given the high BMEP rates and specific power targeted by the project. This section briefly discusses how this was achieved and compares the performance of the adopted port with a current production turbocharged DISI engine benchmark.

Initially, a target was agreed upon based on the JLR engine database and the knowledge of the other partners. Several ports were then designed which fitted the cylinder head package. With these ports designed, CD-adapco then brought 
their capabilities to bear in two distinct parts of the process: a first simulation period where the steady-state flow characteristics were determined using the STAR-CCM+ software package, and a second stage where full transient in-cylinder simulations were carried out using the STAR-CD and es-ice software packages. Figure 7 shows a port in the test rig model, including the intake runner.

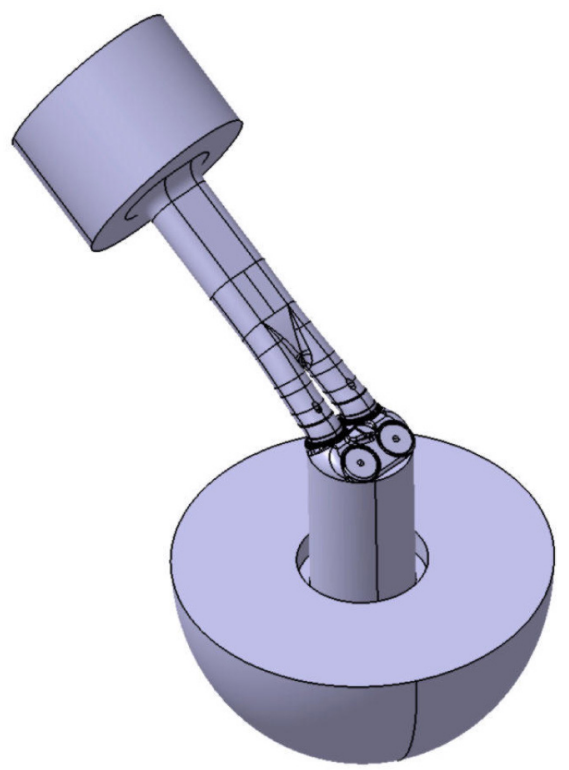

Fig. 7. Intake port and runner within the air flow CFD model

During the first part of this process 20 ports were designed and their steady-state results used to filter the designs. This enabled five port configurations to be carried forward to the second analysis stage, from which a single port was chosen and then machined into the first UB100 cylinder head; this port, known as IP18, is shown in Figure 8, together with the exhaust port. The other available heads were held back from machining should any changes found to be necessary from the first engine test results in Phase 2.

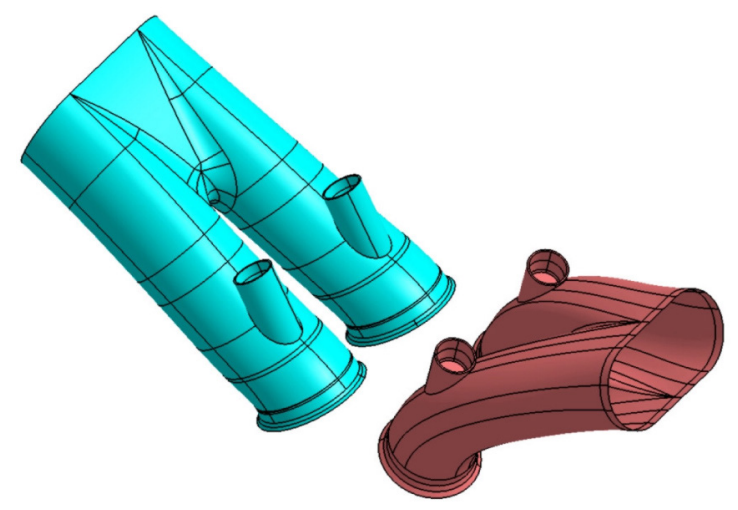

Fig. 8. Final intake ('IP18') and exhaust ports

The ports were flow tested on Lotus Engineering's cylinder head air flow bench. These results were compared to data from the BMW N20 2.0 litre 14 engine which had also been measured on the same flow rig. Although the N20 engine is rated at a BMEP level significantly below that which Ultraboost was targeting, it was still considered to be the state-of-the-art in terms of specific power and BMEP at that time, coupled with the fact that it had a central DI combustion system employing a multi-hole solenoid injector [4]. The results of this flow bench testing are shown in Figures 9, 10, 11 and are discussed below.

Figure 9 presents the flow capability of the inlet port in comparison with the BMW engine. The Ultraboost flow at the maximum valve lift of $10.5 \mathrm{~mm}$ is $182 \mathrm{CFM}$, and that for the BMW at a similar lift is 139 CFM, representing an increase of $30.9 \%$. Since the Ultraboost intake port has a throat diameter of $28.4 \mathrm{~mm}$ versus $27.6 \mathrm{~mm}$ for the $\mathrm{N} 20$, this is comfortably greater than the $5.9 \%$ increase in throat area, illustrating the advantage of the Ultraboost port design. (Note that in this comparison the valve stems have not been taken into account in determining the difference in throat areas.)

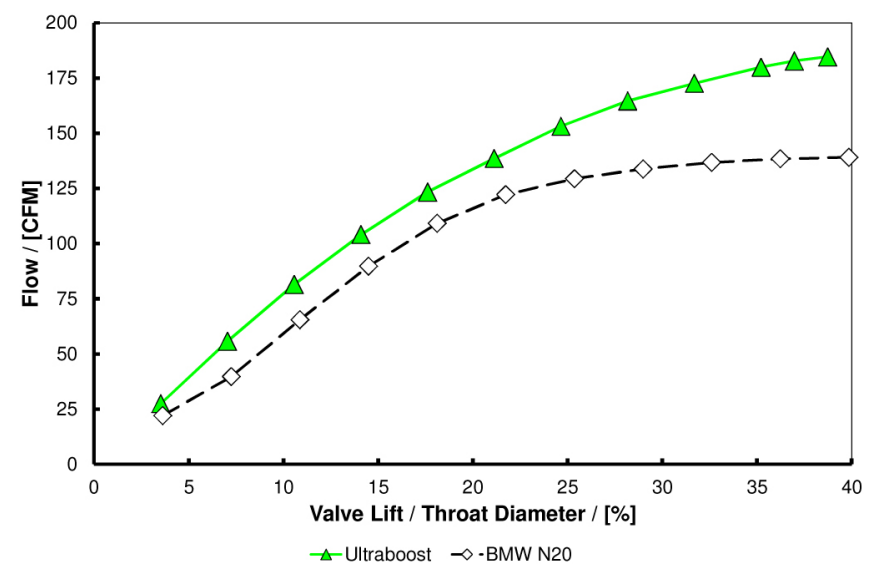

Fig. 9. Intake port flow comparison for the Ultraboost and BMW N20 engines

Figure 10 shows the flow coefficients, with Ultraboost having 0.633 and the BMW 0.520 at the same $10.5 \mathrm{~mm}$ valve lift condition. From this it can be seen that the port flow performance of Ultraboost in comparison to the N20 is extremely good, despite the Ultraboost engine having a smaller bore than the BMW (83 $\mathrm{mm} v 84 \mathrm{~mm})$.

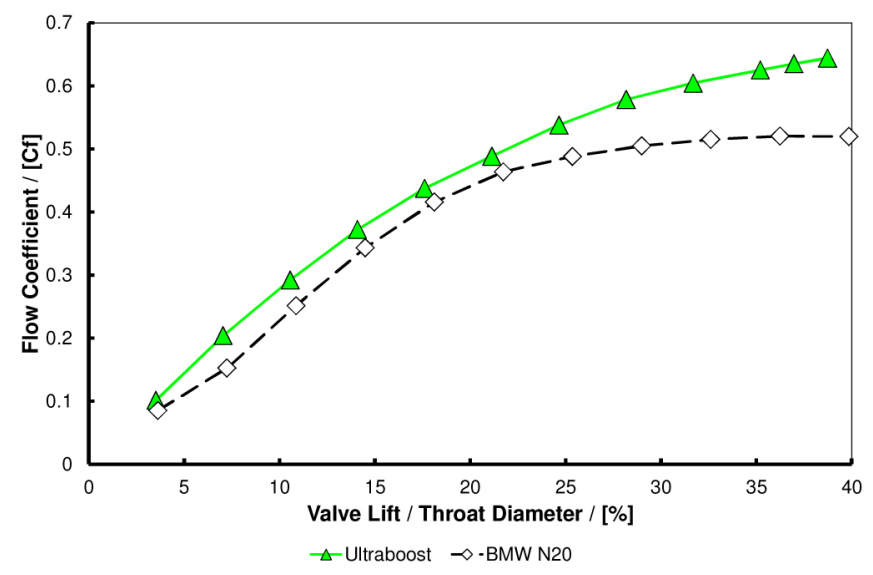

Fig. 10. Intake port flow coefficient comparison for the Ultraboost and BMW N20 engines 
A comparison of non-dimensional tumble number is made in Figure 11. The N20 offers significantly higher tumble at low lift, but it must be borne in mind that it employs valve shrouding in order to increase tumble in this area of the curve, a specific requirement because of its use of Valvetronic mechanicallyvariable valve train [4]. The adoption of this form of valve train makes it especially important to generate sufficient tumble at low valve lifts, since valve lift and duration are the primary means of controlling load while minimizing throttling loss. As a consequence Valvetronic only utilizes the high lift region during high load operation, and so a compromise here is presumably considered acceptable for the N20 engine.

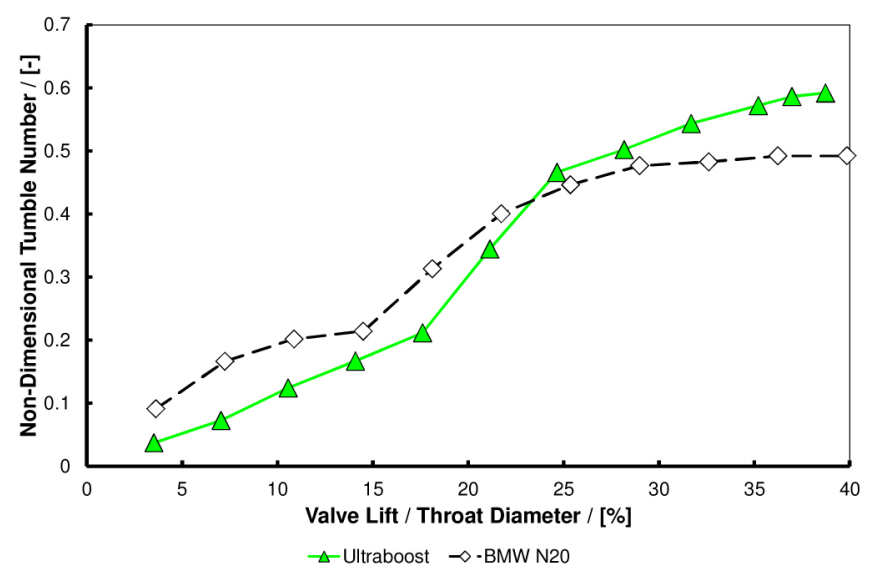

Fig. 11. Intake port non-dimensional tumble number comparison for the Ultraboost and BMW N20 engines

In comparison, Ultraboost was only ever to be fitted with two-step CPS tappets and so high outright tumble rates were considered to be more important, even for part-load operation; greater in-cylinder air motion would be the result albeit at the expense of increased throttling loss. The use of shrouding in the BMW is reflected in the values for the tumble ratio for the two ports, with Ultraboost having 1.626 and the BMW 1.868.

The fact that the adopted port shows high tumble performance throughout the majority of the effective high-lift cam profile from $7 \mathrm{~mm}$ to $10.5 \mathrm{~mm}$ - was considered a success, especially when paired with the high flow coefficient. As a consequence of the air flow rig testing and the engine test results gathered during Phase 2, the IP18 intake port was not changed at all throughout the project.

\section{UB100 Engine Specification}

The general configuration of the UB100 engine, as initially built for testing, is given in Table 1. The undersquare nature of the engine is readily apparent. CAD images of the engine in UB100 specification are shown in Figures 12 and $\underline{13}$.
Table 1. Ultraboost UB100 engine specification

\begin{tabular}{|c|c|}
\hline $\begin{array}{l}\text { General } \\
\text { architecture }\end{array}$ & $\begin{array}{l}\text { 4-cylinder in-line with } 4 \text { valves per } \\
\text { cylinder and double overhead camshafts }\end{array}$ \\
\hline Construction & $\begin{array}{l}\text { All-aluminium } \\
\text { AJ133 cylinder block converted to } \\
\text { single-bank operation on the A Bank } \\
\text { (right-hand side) } \\
\text { Siamesed liner pack to facilitate } \\
\text { reduced bore diameter } \\
\text { Dedicated cylinder head }\end{array}$ \\
\hline Firing order & $1-3-4-2$ \\
\hline Bore & $83 \mathrm{~mm}$ \\
\hline Stroke & $92 \mathrm{~mm}$ \\
\hline Swept volume & $1991 \mathrm{cc}$ \\
\hline $\begin{array}{l}\text { Combustion } \\
\text { system }\end{array}$ & $\begin{array}{l}\text { Pent-roof combustion chamber with } \\
\text { asymmetric central direct injection and } \\
\text { spark plug } \\
\text { High-tumble intake ports } \\
\text { Auxiliary port-fuel injection } \\
\text { Possible second spark plug position in } \\
\text { an under-intake-port location }\end{array}$ \\
\hline Compression ratio & $9.0: 1$ \\
\hline Valve gear & $\begin{array}{l}\text { Chain-driven double overhead } \\
\text { camshafts with fast-acting dual } \\
\text { continuously-variable camshaft phasers } \\
\text { (DCVCP) } \\
\text { Cam profile switching (CPS) tappets on } \\
\text { inlet and exhaust }\end{array}$ \\
\hline $\begin{array}{l}\text { Engine } \\
\text { management } \\
\text { system }\end{array}$ & Lotus 'T6' ECU \\
\hline
\end{tabular}

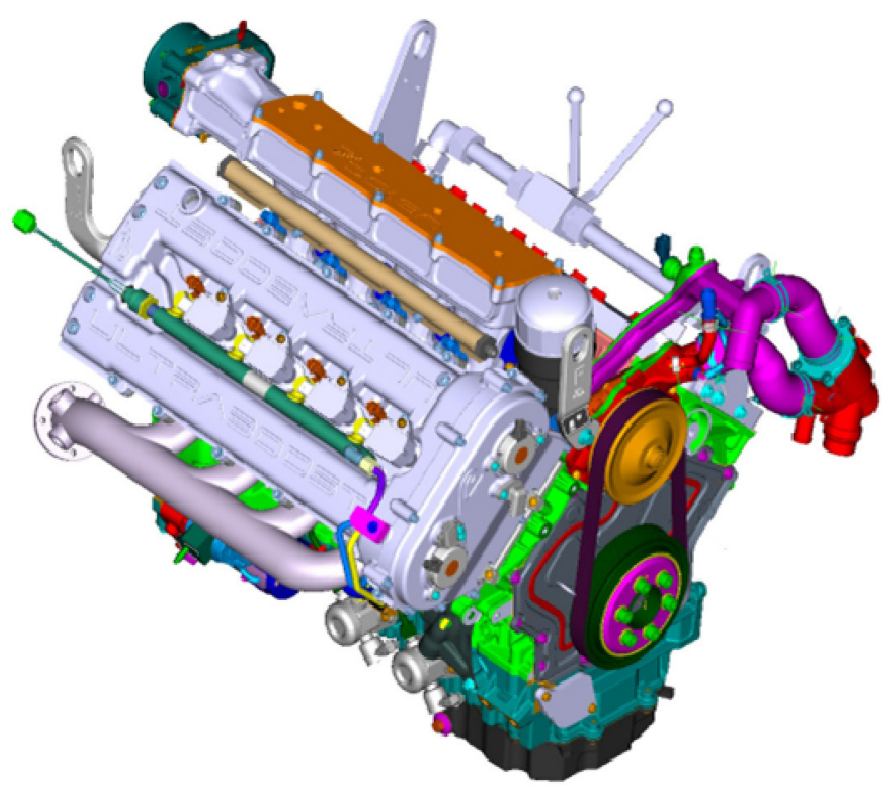

Fig. 12. CAD image of front three-quarter of assembled UB100 engine, as originally tested; note coolant bypass pipe for the absent B Bank cylinder head 


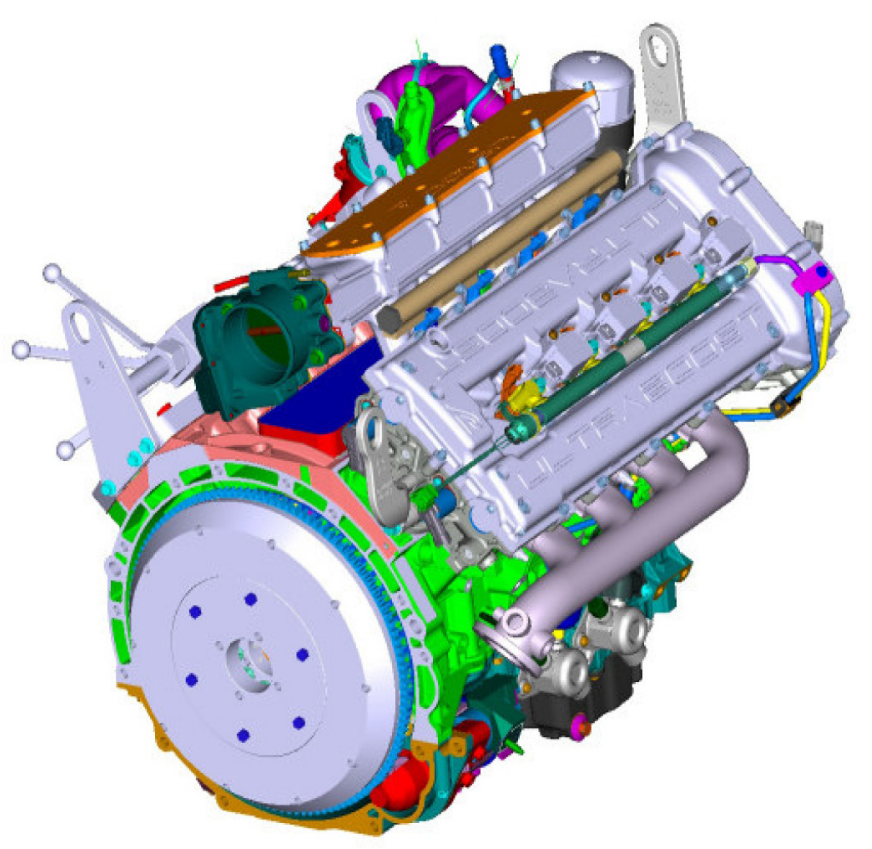

Fig. 13. CAD image of rear three-quarter of assembled UB100 engine, as originally tested with log-type exhaust manifold

\section{Major Additional Technologies Employed on the UB200 Engine}

The chief differentiator between the UB100 and UB200 hardware was the fitment of the engine-driven charging and associated low-pressure cooled EGR systems to the core engine. During Phase 2 the 1-D model was extensively used to help specify this, with several different technologies and technology combinations being investigated. This work was described in detail in a previous paper [므] but, in summary, a series system was adopted using a Garrett GT30 turbocharger as a low-pressure stage and an Eaton R410 supercharger as a high-pressure stage, with chargecooling after each stage.

The supercharger was clutched so that it could safely be driven at a high ratio to the crankshaft at low engine speeds, in order to compound the boost pressure available from the turbocharger, in turn enabling a match for that device more favourable for maximum power. The supercharger also provided improved driveability from low engine speeds and mass air flow rates. Figures 14 and 15 show CAD images of the UB200-level build; in these the UB100 core engine can be discerned by comparison to Figures 12 and $\underline{13}$.

This system has certain similarities to that employed on the Volkswagen Group's 'Twincharger' engines [10,14], except that for the Ultraboost engine the configuration was fundamentally different insofar as the turbocharger was the first stage in the charge air path. This configuration was chosen for several reasons, including the ability to interpose an intercooler between the charging stages in addition to another within the plenum.

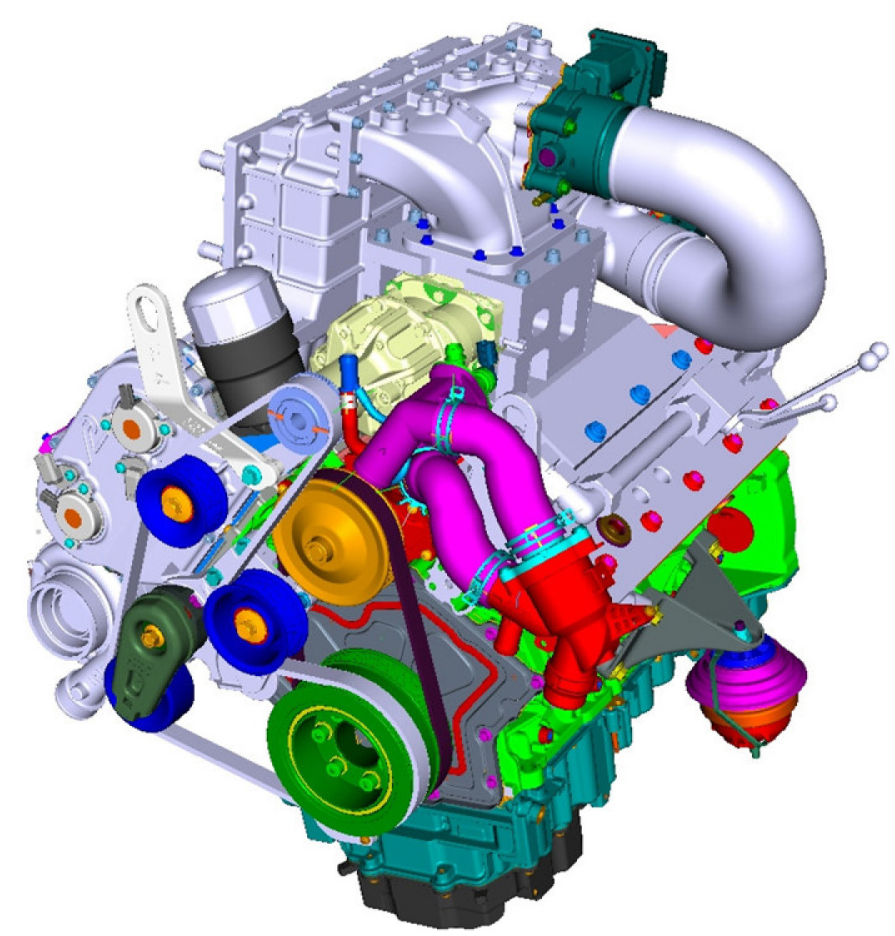

Fig. 14. CAD image of front three-quarter of assembled UB200 engine, showing supercharger and drive belt

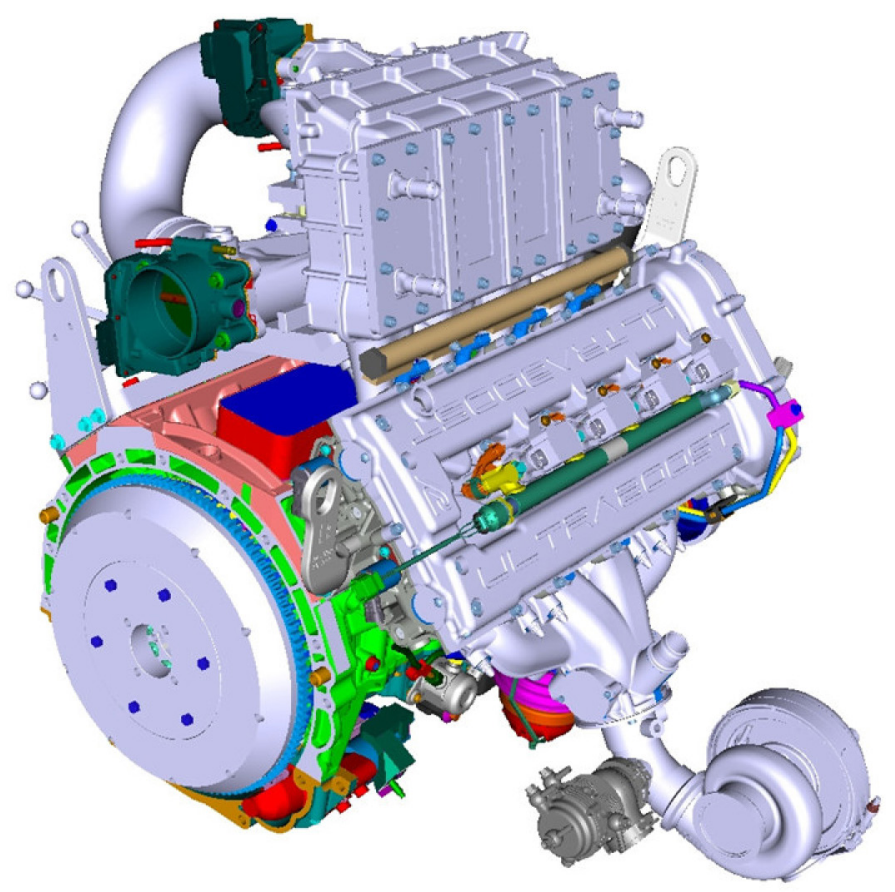

Fig. 15. CAD image of rear three-quarter of assembled UB200 engine, showing water-cooled exhaust manifold and plenum chamber with integrated chargecooler

When the supercharger was declutched the turbocharger effectively blew through two chargecoolers in series, ensuring high chargecooler system effectiveness overall. Conceptually, the Ultraboost system was very similar to the charging system employed by the Lancia Delta S4 rally car [21], except that in that application the supercharger was not clutched out (although 
it was bypassed), and so was necessarily quite large. For the Lancia this was done to provide the best driveability possible within the constraints of the control systems of the time.

In turbocharged engines, chargecoolers are conventionally placed before the throttle so that their volumes are always at least at atmospheric pressure and therefore take less time to fill during a boost transient. Fitting a chargecooler in the plenum requires the minimization of its volume to minimize filling time; this in turn makes liquid-cooled chargecoolers desirable, because of their high air-to-water heat exchanging effectiveness. The high-pressure charge air cooler used in the UB200 builds consisted of two large units welded together in parallel and sited in the flow path directly within the plenum, whose volume was therefore kept to a minimum. The form of the duct feeding air to the chargecooler bricks was optimized using CFD to ensure even distribution and hence even air temperature for the charge flowing to the intake ports. The general form of the plenum can be discerned in Figure 15.

Were the engine ever to be have been fitted to a vehicle, the first-stage charge cooling stage would probably have been air-to-air and hence it would have been vehicle-mounted. For this reason it was replaced with a liquid-cooled heat exchanger on the test bed.

Operation within the metallurgical limits of the supercharger was one of the important boundary conditions which the 1-D model helped to investigate; this boundary condition was further compounded by any cooled EGR found to be necessary in order to limit turbine inlet temperature (TIT) to less than $1050^{\circ} \mathrm{C}$, or to help offset the knock limit. Similar observations applied to the turbocharger compressor, since this received the EGR after it had been cooled only by the EGR cooler and then mixed with fresh air, thus increasing its intake temperature above atmospheric. There is some offset of this effect in the lower ratio of specific heats of the exhaust gas component, but one can readily appreciate the importance of good cooling effectiveness for the EGR gas.

To further assist with limiting TIT directly on the exhaust side, a water-cooled exhaust manifold (WCEM) was fitted, which can be seen in Figure 15. Over the last few years the integrated exhaust manifold (IEM) has become a common technology for production engines $[\mathbf{7}, \underline{8}]$, having been found to be particularly advantageous in turbocharged engines because it allows the removal of a large degree of component protection overfuelling at high load $[\underline{9}, \underline{22}]$.

Unfortunately, because of the large bore and cylinder head bolt pitches inherited from the AJ133 engine, it was not feasible to design an IEM into the Ultraboost cylinder head. However, there was an interest in investigating a WCEM from the point of view of assessing full-load heat rejection. More importantly it allowed a more advantageous exhaust path geometry than that of the log manifold originally specified and used in the initial UB100 testing in Phase 2, and mitigated the fact that the original's outlet geometry was restrictive (see later). It also permitted the provision of a flow splitter which could separate all the cylinders completely, pulse-divide cylinders 1 and 4 from 2 and 3 , or permit full mixing (all at the entry to the turbine). The final design of the WCEM is shown in Figure 16, where the position for the flow splitter can be seen. Its water jacket is also shown; water flows from a distribution manifold below the individual feeds, combines within the jacket and then flows out through a single pipe on the top near to the gas outlet. The difficulty in incorporating the manifold into the cylinder head and retaining short gas-wetted paths is apparent from these images.
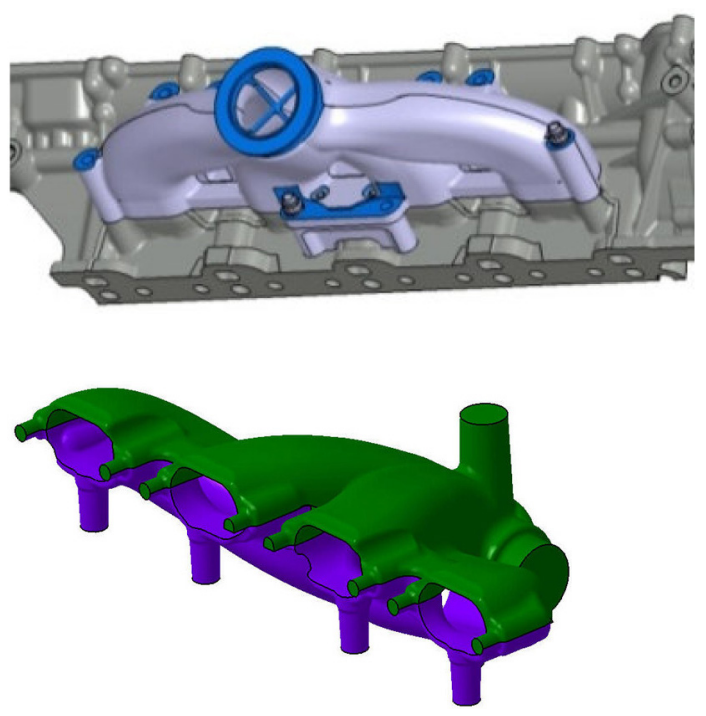

Fig. 16. Water-cooled exhaust manifold (WCEM). Top: view showing position at which a flow splitter could be placed; bottom: water jacket

The WCEM utilizes water flowing through the B bank bypass loop with appropriate valving to ensure the correct flow rate through it and the oil cooler.

\section{UB200 Engine Specification}

Data pertaining to the charging, cooled EGR and engine management systems specific to the UB200 build level is given in Table 2; other engine data is as per Table 1, there having been found to be no need to redesign the core engine as a result of the test work carried out in Phase 2 using UB100. The only other difference between the two engine levels was in the EMS employed, which is discussed in the next section.

A photograph of the major charging system components added to UB100 to create the UB200 specification is shown in Figure 17. From this the relative size of the WCEM, turbocharger and water-cooled charge air cooler can be ascertained. 
Table 2. UB200-specific charging, cooled EGR and engine management systems

\begin{tabular}{|l|l|}
\hline $\begin{array}{l}\text { Low-pressure } \\
\text { charging system } \\
\text { stage }\end{array}$ & $\begin{array}{l}\text { Garrett GT30 turbocharger with } \\
\text { separate wastegate }\end{array}$ \\
\hline $\begin{array}{l}\text { Inter-stage charge } \\
\text { air cooler }\end{array}$ & $\begin{array}{l}\text { Off-engine water-cooled charge air } \\
\text { cooler; effectiveness set to mimic } \\
\text { typical vehicle-mounted systems }\end{array}$ \\
\hline $\begin{array}{l}\text { High-pressure } \\
\text { charging system } \\
\text { stage }\end{array}$ & $\begin{array}{l}\text { Clutched Eaton R410 supercharger with } \\
\text { overall 5.6:1 drive ratio (later changed } \\
\text { to 5.9:1 - see text) } \\
\text { Full-flow supercharger bypass }\end{array}$ \\
\hline $\begin{array}{l}\text { After-stage charge } \\
\text { air cooler }\end{array}$ & $\begin{array}{l}\text { Water-cooled charge air cooler, } \\
\text { mounted in the intake plenum after the } \\
\text { main throttle }\end{array}$ \\
\hline EGR system & $\begin{array}{l}\text { Off-engine low-pressure loop } \\
\text { configuration with EGR control valve } \\
\text { placed after the EGR cooler }\end{array}$ \\
\hline $\begin{array}{l}\text { Engine } \\
\text { management } \\
\text { system }\end{array}$ & \begin{tabular}{l} 
Lotus Euro 8' ECU \\
\hline
\end{tabular}
\end{tabular}

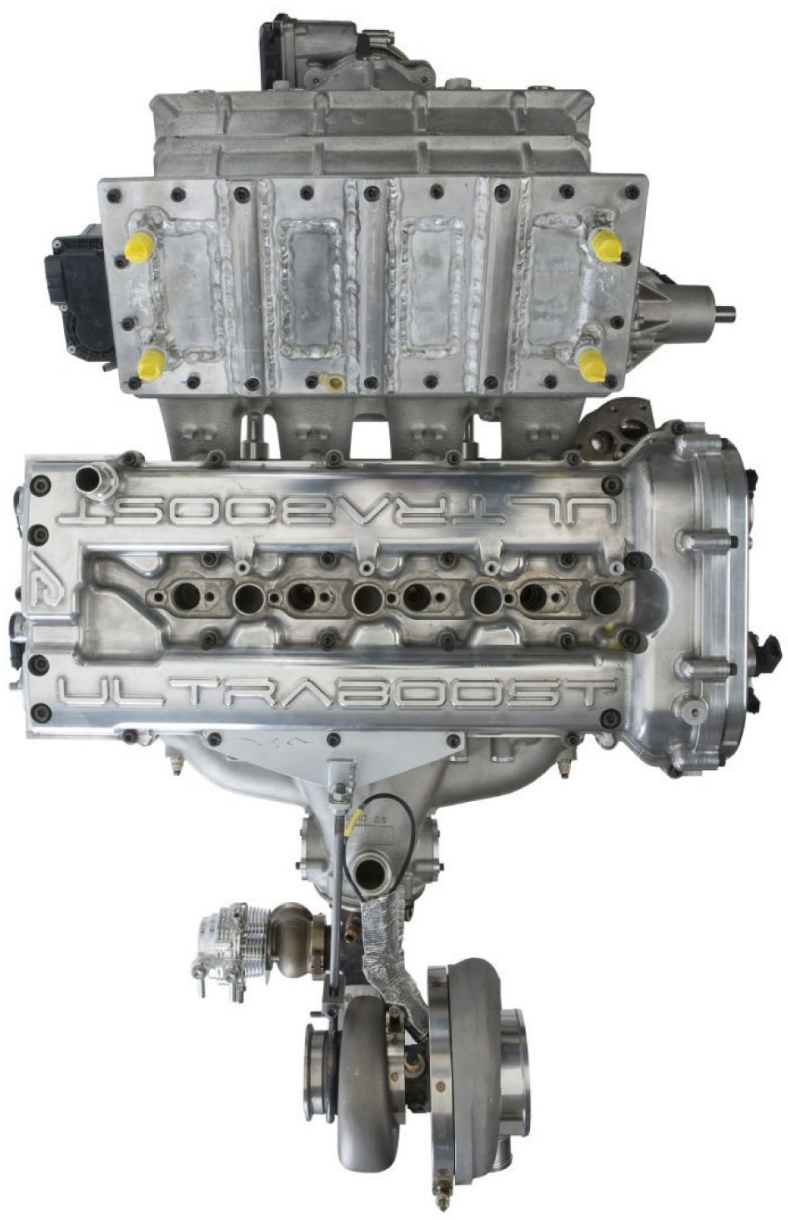

Fig. 17. Photograph of UB200 charging system components assembled onto cylinder head

\section{ENGINE MANAGEMENT SYSTEM}

The EMS employed throughout the three project phases was engineered and supplied by Lotus. In Phases 1 and 2 the 'T6'-type EMS was used, as found on Lotus production vehicles; for Phase 3 the 'Euro 8' controller was used. The following sections discuss these control systems and how they were applied.

\section{UB100 EMS}

During Phase 1, in which the Jaguar Land Rover AJ133 V8 engine was operated on the test bed at the University of Bath, it was necessary to establish benchmark targets using the production Denso ECU. In order for the T6 EMS to assume this role a hot test rig was initially used gradually to take over the original EMS sensor and actuator functions. This included adapting it to the AJ133 crankshaft and camshaft sensor tooth patterns and providing new functionality in the form of control of the fast-acting DCVCP system (the electro-hydraulic nature of which had not been controlled using this EMS before), control of the dual high-pressure fuel pumps and cam profile switching (CPS) tappets, and the requirement to apply multiple injection and ignition strategies. Once the Denso EMS had been fully replaced and satisfactory operation established on the hot test rig the T6 EMS was applied to the engine on the dynamometer at the University of Bath.

Prior to this, the AJ133 engine had been baselined with the Denso EMS at Bath in order to confirm JLR's expected performance, emissions and fuel economy figures and sign it off. The project-specific minimap test points, as determined by modelling, were run and the data gathered for later comparison purposes. The T6 EMS was then fitted and showed excellent performance versus the original system in terms of full-load torque, emissions and fuel economy at the set minimap points: the average results for these points were less than $1 \%$ lower. The T6 EMS was therefore signed off for Phase 2 of the project and the AJ133 V8 engine was replaced by the first UB100 build for testing.

Several new functions were required to control the UB100 engine over those which had been established for the AJ133 V8 engine. While some of the complexity was notionally removed with the deletion of one bank, new functionalities were added for the separate control of the CPS tappets on the intake and exhaust sides, control of the PFI and DI systems, and the movement from a throttle-angle to a speed-density control philosophy (made necessary by the fact that the engine was now to be boosted). All of this had to be done in order to control the engine for the test programme described later. However, there was no requirement during Phase 2 of the project to control any components of the air charging or EGR systems, since the University of Bath's CAHU and EGR rig were used and were separately controlled by the test cell for these functions (see Test Facility description below). This was 
particularly helpful during a research project like this where the individual parameters could be controlled independently of each other

The UB100 fuel system comprised the high-pressure DI pumps from AJ133, pipework to combine their delivery and a modified standard fuel rail arrangement. Standard Bosch DI injectors from JLR's AJ126 supercharged V6 engine were used, the rationale for which choice being that these would be supplemented by low-pressure PFI as and when required. These DI injectors have the same flow rate as the AJ133 items. The reduction in exhaust system component protection fuelling associated with the water-cooled exhaust manifold and the employment of cooled EGR, coupled to an expected reduction in exhaust back pressure associated with improved specific air consumption and the improved mechanical efficiency versus the AJ133 (in turn requiring reduced air flow to produce the same power), were expected to require the use of DI solely over most of the operating range. The PFI system was fed by a rail in the feed line to the high-pressure pumps, and they operated at 4.5 bar above boost pressure. Maximum injection pressure for the DI system was 200 bar, higher than the 150 bar maximum of the standard AJ133 [18].

Initial operation of the UB100 engine followed a gradual process of engine speed and load increase, with the functionality of the different engine systems being established at pertinent points in the programme. Successful operation of the DCVCP and CPS functions was demonstrated early on, followed by speed-density control and DI/PFI split ratio.

The EMS communicated with the test cell via ASAP3 software.

\section{UB200 EMS}

Once the outline of the Phase 3 design was known (and particularly the configuration of its charging system), work began on choosing the most suitable EMS unit for this phase. Compared to the relatively simple T6 EMS used on the UB100 engine in Phase 2, the system destined for UB200 (shown in Figure 18) had to incorporate the following additional sensors and actuators simply to control the charging system:

- Additional temperature, pressure and TMAP sensors at various positions in the charging system

- Mass air flow sensor (via two air boxes as used for the original AJ133 engine)

- Turbocharger shaft speed sensor

- Supercharger shaft speed sensor (in order to verify engagement and to detect belt slip)

- Wide range air-fuel ratio (AFR) sensor

- EGR temperature sensor

- Turbocharger wastegate actuator

- EGR valve position sensor

- Supercharger bypass valve actuator

- Supercharger clutch position sensor

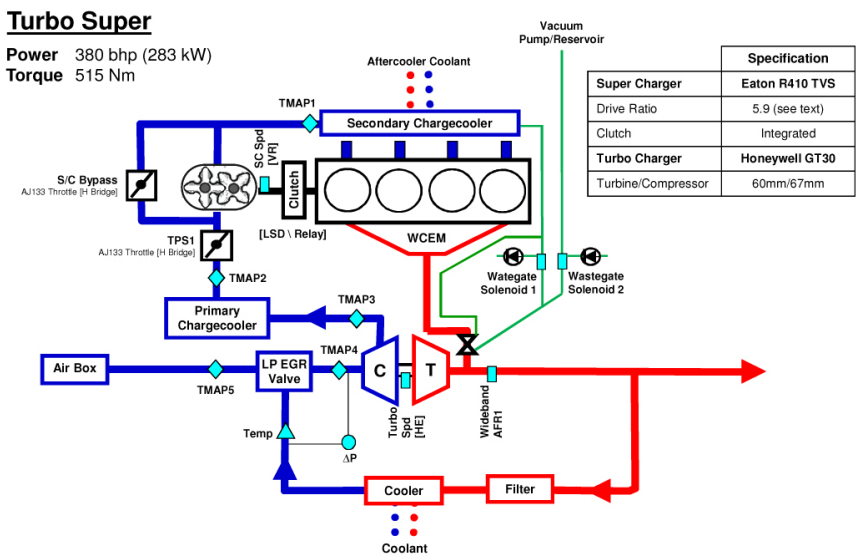

Fig. 18. Schematic of the air management module and EGR estimation subsystem of the Lotus Euro8 EMS

Due to the functional requirement to be able to bypass all of the charge air around the supercharger when it was declutched, the bypass valve had to be of a large diameter and also have a high resolution of control for the region of switchover from one charging regime to the other. This resulted in the adoption of an $\mathrm{H}$-bridge controlled electronic throttle for this function. The EGR valve also needed to be controlled with similar precision. With the main throttle itself this meant that the system required three $\mathrm{H}$-bridge throttle control devices in total. Since the T6 ECU only had provision for two H-bridge devices this situation was instrumental in the decision to upgrade to a new type of pre-production ECU (known as Euro8) for Phase 3. There were a number of other hardware advantages in moving to the Euro8 system including the inclusion of on-board wide range AFR measurement capability. As well as these improvements to component drivers another major influence in deciding to upgrade was the significant increase in available RAM and processor speed. This meant that there would be no development restriction on the size of the rapid prototype Simulink models that could be auto-coded and the processor would be able to cope easily with the increased computational requirements.

After the success of debugging the T6 system using a hot test stand the same approach was used with the UB200 engine and its new ECU with additional sensors and actuators. This meant that all commissioning was done locally at Lotus, leaving the University of Bath facility free to continue testing the UB100 level engine.

From a software perspective Phase 3 required two major control additions. These were an enhanced air management module and an EGR estimation subsystem. These are shown schematically in Figure 18. As alluded to previously the development method of choice was to use Simulink. This was considered essential to help model the response of what was to be a very complicated system ahead of any test hardware being available. The resultant models were auto-coded and placed within the embedded code set. 
The air management module consisted of four main subsystems. The first read in the percentage load demand and, taking into account current operating conditions and an estimate of the current EGR percentage, determined the manifold pressure required to achieve the desired load. It then apportioned this to individual target compressor and supercharger outlet pressures, taking into account turbocharger performance limitations. From this, it calculated target pressure ratios across the turbo compressor, the main control throttle (labelled as TPS1 in Figure 18) and the supercharger bypass. Finally it estimated the current supercharger bypass flow.

The second subsystem used this information to control the manifold pressure via the main load control throttle, 'TPS1', when the required pressure ratio between compressor outlet and manifold was less than unity. The TPS1 control strategy operated in terms of flow area with open- and closed-loop strategies applied.

The third subsystem controlled the boost actuators individually (i.e. the turbocharger wastegate and the supercharger bypass valve). The supercharger bypass took over control from TPS1 to boost the compressor outlet pressure up to demanded manifold pressure when required. Wastegate control was modulated in a closed-loop manner to achieve target compressor pressure when the demand was above the current natural boost value. When active, the supercharger bypass and wastegate demands were determined using traditional open- and closed-loop control with anti-windup and limitation logic applied.

The open- and closed-loop control activation requests for each actuator came from the fourth subsystem, which contained the main air path state machine. This output control subsystem determined which mode of operation the system was in and ensured correct and seamless transition between the modes. It also had final authority over the actuator demands. The system developed for Phase 3 had six modes of air path operation. These modes were as described below.

\section{Minimum boost}

Supercharger clutch disengaged, supercharger bypass open, wastegate open, TPS1 control only.

\section{Supercharger clutch engagement}

Supercharger clutch engagement procedure (to minimize torque dip) in progress.

3. Turbocharger and supercharger - TPS1 control

For pressure ratios < 1 : supercharger clutch engaged, supercharger bypass open, TPS1 control.

4. Turbocharger and supercharger - supercharger bypass control

For pressure ratios $>1$ : supercharger clutch engaged, supercharger bypass control, TPS1 open.

5. Turbocharger only - minimum boost

For pressure demands < natural boost: wastegate open, TPS1 control

\section{Turbocharger only - active wastegate}

For pressure demands > natural boost: wastegate control and TPS1 control

With the complexity of all these control functions it was not possible to run transients safely without a good baseline steady-state calibration. In order to do this it was essential to have in place a large number of manual overrides to assist the University of Bath with getting both steady state results and sufficient system stability to conduct the calibration exercise. These included direct control of all the air path actuators and the manifold pressure control system. Only then was fullyautomatic target load control employed.

In previous phases, the required amount of cooled EGR was pumped into the pressurized intake system using a purpose built rig (see next section). For the purposes of the standalone UB200 build, a 'long route' or low-pressure EGR path was chosen. This entailed taking the post-turbine exhaust gases and introducing them just prior to the compressor entry, a location that facilitated good mixing given both the nature of the compressor and its distance from the intake plenum. To introduce the required amount of residual gas, a subsystem was designed to calculate the cooled EGR flow rate using the pressures and temperatures in the exhaust and intake system as well as the EGR valve position. The calculation routine made use of an effective valve-open area mapped against a valve opening angle for a range of pressure ratios and densities. The flow characteristics of the system were first understood on an air flow bench where a variety of conditions were tested to verify the principles upon which the algorithm was based.

The amount of residual gas required, derived through prior calibration, was specified as a percentage of the intake volumetric flow and stored in a look-up table. The required EGR flow rate was then calculated and in conjunction with the existing pressure gradients, used to determine a valve opening angle which would then either meter or facilitate the flow of exhaust gas into the intake. For example, only a small valve opening was required to meter the flow of EGR if a favourable pressure gradient existed to drive the flow of exhaust gas into the intake system. However, when the exhaust driving pressure fell below that of the intake system, the EGR valve was commanded to open to a position that created the correct downstream depression to facilitate the flow of exhaust gas. Correct calibration of the system enabled a smooth transition between these two modes of operation thus forming the capability of dealing with system pressure fluctuations. The system is open loop in control reacting only to changes in demand and changes in pressure and temperature either side of the EGR valve. Both hardware and software provision existed, however, to achieve closed-loop control by reading back the oxygen content in the intake plenum via a fast-acting oxygen sensor. This may prove to be an important control input in future engines using cooled EGR. 


\section{TEST EQUIPMENT}

\section{Test Facility}

All of the Ultraboost engine development work was undertaken on one of the University of Bath's transient engine facilities. The facility used featured a twin dynamometer arrangement with a $220 \mathrm{~kW}$ AVL AC dynamometer supplemented by a Froude eddy current brake to allow additional absorption up to the expected torque and power rating of the Ultraboost engine. Maintaining the AC dynamometer allowed motoring work to be undertaken for controller debugging, friction tests and improved transient response during time-to-torque testing. All control and data acquisition was performed using a Sierra-CP CADET V14 control system. In addition to standard temperatures and pressures, the specific experimental hardware shown in Table $\underline{3}$ was used. Interfaces to the combustion analysis, EMS (with ASAP3 interface), emissions analyzers, CAN instruments, and conditioning of combustion air, fuel and cooling circuits were all achieved through the CADET V14 software.

Table 3. Test equipment

\begin{tabular}{|l|l|}
\hline Engine speed & 1024 pulse/rev encoder \\
\hline Engine torque & $\begin{array}{l}\text { HBM T10f 1 kNm torque measurement } \\
\text { flange }\end{array}$ \\
\hline & $\begin{array}{l}\text { AVL Indimaster advanced 16 channel } \\
\text { system. } \\
\text { AVL 3600 pulse/rev optical encoder } \\
\text { Kistler 6054A in-cylinder transducers } \\
\text { Kistler 4041B water-cooled in-cylinder } \\
\text { transducer } \\
\text { Kistler 4049A water-cooled exhaust } \\
\text { pressure transducer } \\
\text { Kistler transducer cooling module and } \\
\text { analysis }\end{array}$ \\
& ABB Sensyfifiers 1200 kg/h \\
\hline Air flow & $\begin{array}{l}\text { CP Engineering FMS 1000- 1 litre } \\
\text { gravimetric fuel weigher } \\
\text { Coriolis flow meter }\end{array}$ \\
\hline Fuel flow & $\begin{array}{l}\text { 2off MEXA 7100 DEGR exhaust gas } \\
\text { analysers for simultaneous pre- and post- } \\
\text { catalyst sampling } \\
\text { AVL 439 Opacimeter } \\
\text { Cambustion DMS 500 particulate } \\
\text { sizer/counter }\end{array}$ \\
\hline ETAS LA4 Lambda meter \\
\hline Emissions & $\begin{array}{l}\text { Labcell pressure-compensated Lambda } \\
\text { CAN }\end{array}$ \\
\hline AFR & Labcell blowby meter \\
\hline $\begin{array}{l}\text { Intake manifold } \\
\mathrm{O}_{2} \%\end{array}$ & $\begin{array}{l}\text { Up to 32 K-type thermocouples, 16 PRTs } \\
\text { and 16 pressure channels, coolant flow rate } \\
\text { (Krohne magnetic flow meter) }\end{array}$ \\
\hline Engine blowby \\
\hline $\begin{array}{l}\text { Other } \\
\text { measurements }\end{array}$ \\
\hline
\end{tabular}

During Phase 2 testing with the UB100 engine, in order to characterize the combustion system the CAHU was used to simulate the intake air conditions expected from the specified boosting hardware. The system actively controlled the boost pressure, EBP and air charge temperature. EBP was controlled by a butterfly valve located on the exit of the exhaust manifold and was used to replicate the pressure that would be expected due to the presence of a turbine. In addition to these systems an EGR pump was developed to pump the cooled EGR gas into the inlet system; due to the CAHU using industrial compressors there is no low-pressure point to introduce the EGR gas. The schematic in Figure 19 shows the gas path of the EGR pump rig.

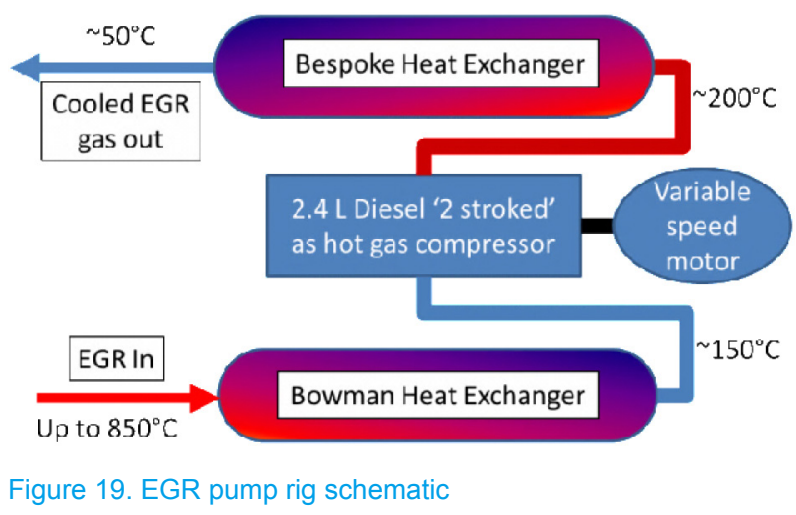

Exhaust gas was taken post-EBP valve and cooled using a Bowman heat exchanger. After being compressed the gas was cooled again and then introduced upstream of the inlet manifold to allow for adequate mixing. A variable-speed electric motor allowed control of the EGR flow rate up to $20 \%$ across the engine speed range. The combined use of the EGR pump facility and the CAHU allowed for a controlled investigation into the effect of different EGR rates at a number of engine speeds with independent control of all engine inputs. Specific tests using catalyzed and uncatalyzed EGR were conducted and will be reported separately [23].

A photograph of the UB100 engine on the test bed at the University of Bath is shown in Figure 20.

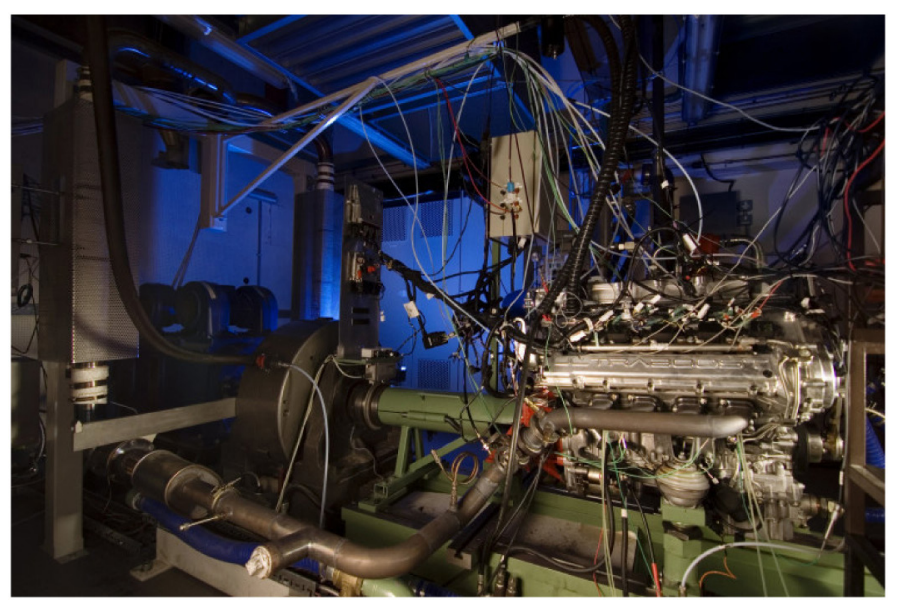

Fig. 20. Ultraboost Phase 1 engine on the test bed at the University of Bath 


\section{Test Fuels}

The base fuel used throughout the engine development process and all of the testing described here is an EN228 compliant UK market gasoline, sourced from Shell Global Solutions. The fuel was transported from the Shell Technology Centre Thornton to the University of Bath in 1000 litre individual bulk containers (IBCs) as required. Its characteristics are shown in Table 4.

Table 4. Details of base fuel formulation

\begin{tabular}{|c|c|}
\hline RON & 97 \\
\hline MON & 85.3 \\
\hline Sensitivity & 11.7 \\
\hline LHV $(\mathrm{MJ} / \mathrm{kg}$, gas $)$ & 43.1 \\
\hline Density $\left(\mathrm{g} / \mathrm{cm}^{3}\right)$ & 0.743 \\
\hline Oxygenate content & E5 \\
\hline
\end{tabular}

An additional matrix of 14 fuels was tested in the Ultraboost UB100 engine, in order to probe the response of a highlyboosted, downsized engine to a variety of fuel properties, including octane number, sensitivity (defined as RON minus MON), flame speed and oxygenate content. The use of the CAHU and EGR rig permitted very tightly controlled boosting conditions, and were found to be ideal for such tests. The results of the specific fuel experiments will be reported elsewhere [24].

\section{ENGINE TESTING}

\section{Testing of the UB100 Engine during Phase 2}

The first build of the UB100 engine was hot tested on site at JLR before being sent to the University of Bath, to check for compression pressures and cooling system functionality, before being fitted to the test bed and commissioned with no issues. Initial operation was at the NA condition, with the 1-D model being used to define exhaust back pressures and to help understand the best cam timing settings to use. After this initial commissioning work, the University of Bath then commissioned the CAHU and this was used to increase the load into the pressure-charged region.

In order to simplify the testing process, the 1-D model was extensively used to set the intake conditions for the CAHU and the related exhaust back pressure so that, in the area where both charging devices worked in series, so-called 'supercharger-biased' and 'turbocharger-biased' operating conditions could be investigated. This was important to do since with an operating condition biased towards using the high-pressure supercharger to provide boost one expects higher parasitic losses, but with a trade-off in potentially significantly better combustion efficiency (since there is a reduction in the residual gas fraction retained in the combustion chamber from one cycle to the next to promote autoignition). This operating mode must be compared with achieving the same condition by closing the turbocharger wastegate and extracting more work from the turbine instead, in turn lowering parasitic losses but harming scavenging efficiency (particularly important in 4-cylinder engines).

During Phase 2 testing various functions were investigated, including injection timing and duration, cam timing and PFI/DI fuelling split ratios. Cooled EGR was also investigated. Interestingly, within this test programme, during a brief initial test there was found to be no benefit in moving from DI operation to mixed PFI/DI, which is considered to be evidence to confirm the efficacy of the intake ports in terms of mixture preparation and homogenization, coupled with the loss of charge-air cooling due to less effective use of latent heat of vaporization and the effect of increased oxygen displacement with PFI. While a full engine speed and load investigation was not conducted, the condition of $2000 \mathrm{rpm}$ and 2.2 bar Absolute manifold pressure was tested in detail and the results are shown in Figure 21. This test was run with fixed valve timing throughout and the trend with increasing PFI flow can clearly be discerned. Another observation from the results of this test is that in general the knock limit reduced as the proportion of PFI fuelling was increased, which again reinforces the observations made above.

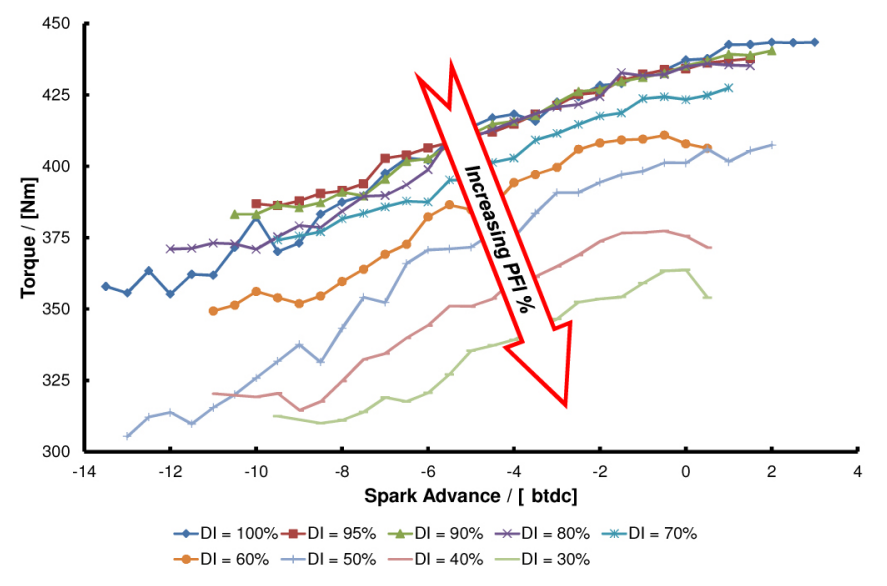

Figure 21. Results of PFI/DI fuelling split ratio test at $2000 \mathrm{rpm}$. Percentage of fuel supplied via DI system shown in key

No particulate matter readings were taken within the DI/PFI split testing; it is accepted that this is an area where other effects might be seen and further research would be beneficial. Furthermore, a fixed start of injection for the PFI system of $55^{\circ}$ atdc overlap was employed throughout this test (i.e., open-valve injection), which may be some way from the optimum; thus it is intended to investigate this in later work as well.

Another interesting and potentially very significant finding was that the engine appeared to show no propensity towards low-speed preignition (LSPI). This gratifying discovery was entirely unexpected, given the issues that other researchers appear to have in this area and the limitations it can impose on 
aggressive engine downsizing. Problems were expected, but when none arose the test programme could be followed rapidly and at the same time it was not found necessary to redesign the UB100 core engine for Phase 3. Indeed, during Phase 2 it was found to be possible easily to operate at over 27 bar BMEP at $1000 \mathrm{rpm}$ (after removing the supercharger drive torque) with no LSPI issues, showing that the combustion system is not a limit to $60 \%$ downsizing. The subject of where the limit is believed to be with this engine will be returned to later.

The exact reason for this unexpectedly good performance with regard to LSPI (and probably the excellent knock resistance found as well) is unknown at the moment, but is the topic of further study. The working hypothesis is that excellent homogenization of the charge in the cylinder has been achieved with the very high activity intake port. This reduced irregularities in the charge due to temperature, burned residuals or oil droplets to a point where they could not act as precursors to autoignition. The central DI arrangement doubtless also assisted this. All of this is in line with recent literature $[\underline{25}, \underline{26}, \underline{27}]$.

It should be stated that the engine was operated throughout with an open breather, it being undesirable to put the breather gases through the CAHU. It also had an undeveloped breather system. Engineering of a properly-functioning breather system with excellent oil extraction is not believed to be an issue for any later production engines utilizing this level of downsizing, however.

In addition to the tests described above, the EGR sensitivity and fuel properties tests were also run during this phase. These are reported elsewhere $[\underline{23}, \underline{24}]$. For most of the Phase 2 testing, after the base performance of the combustion system had been ascertained, the engine was run to help validate the 1-D model and to demonstrate that, after the supercharger drive torque had been taken into account, the target performance would be achievable with the UB200 build and its self-driven charging system. In order to do this the 1-D model was used to set the boundary conditions, but early on, when the log-type manifold was fitted, a gas flow limit was reached which was a result of reduced cross-sectional area in the manifold. This state of affairs had arisen as a consequence of not allowing for the anticipated wastegate flow in the sizing calculations. As a consequence it was decided to accelerate the design and procurement of the WCEM, which corrected this loss in flow area and also provided better manifold tuning.

One set of tests conducted with the CAHU and WCEM fitted was a so-called constant-air-density test. In this, the charge-air density was fixed, and pressure increased with temperature adjusted to hold density constant. As a concept, this was considered important with regard to combustion effects and to gauge the importance of effective charge cooling on combustion. Since the charge air density was fixed then, for a fixed relative air-fuel ratio $(\lambda)$ and level of charge trapping ensured by the valve timing, the chemical energy flowing through the engine would, to a first degree, be constant. Any changes in knock-limited spark advance (KLSA) would therefore primarily be due to the change in end-gas temperature- and pressure-time histories arising from the different start-of-compression states. The rationale for the approach has been discussed previously $[\underline{28}, \underline{29}]$.

This test was only made possible on a multi-cylinder engine because the accuracy of control of the CAHU unit with regard to holding target charge air conditions had previously been found to be extremely good (versus the earlier-reported tests in the literature having to be conducted on a single-cylinder engine because of limitations with that work). This accuracy was $<0.2 \%$ over the range of set-points used throughout engine testing during Phase 2.

The constant air density test was conducted at $1500 \mathrm{rpm}$ and the results, in terms of KLSA, are presented in Figure 22. Immediately apparent is that the response to reduced temperature was essentially linear: for each set of constant charge air density data, as the air temperature was reduced (and the air pressure was reduced concomitantly to maintain the fixed density) KLSA increases monotonically. This is considered remarkable given the non-linearity of both heat transfer effects and combustion kinetics, but the data reinforces the earlier-reported research in this area [28,29], albeit at much higher charge air densities and in a completely different engine utilizing DI. Given this result and its importance, further work in this area is planned for a follow-on project, not least to investigate secondary effects such as the interaction of valve overlap with scavenging pressure as the inlet air temperature and pressure conditions are changed.

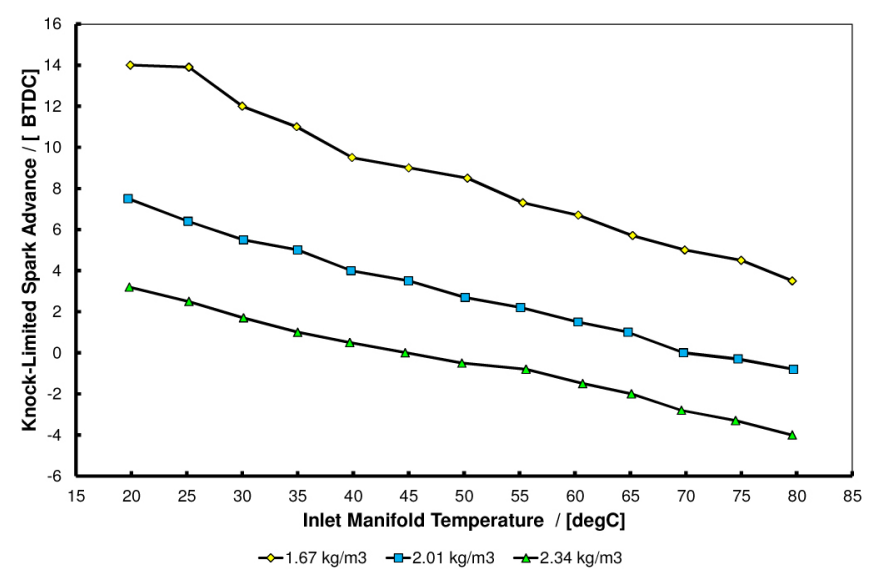

Fig. 22. KLSA versus charge air temperature for constant charge air density tests: UB100 engine operating with CAHU

As already mentioned, during testing at high speed with the original log-type manifold, a flow restriction was found which was due to a lack of capacity for the waste gate flow. The effect of this only became apparent above 4000 rpm as shown in Figure 23 , and this led to the fitment of the WCEM which had been designed to eliminate this problem. However, as the performance was increased with the WCEM fitted another limit was reached. Cylinder 2 appeared to be capable of generating more indicated mean effective pressure (IMEP) than the other 
cylinders for the same spark advance, and the associated higher pressures caused it to reach the PCP alarm first, below the limit of the other cylinders. Examination of the individual cylinder pressure traces and those for the exhaust and intake manifolds showed that a dynamic wave effect was causing this, presumably trapping more mixture in the cylinder. As a consequence it was decided to conduct an early test with the selected Honeywell GT30 turbocharger [20] instead of using the CAHU; the expectation was that the turbocharger turbine would cause the wave dynamics to shift markedly from the constant-pressure conditions afforded by the EBP valve and equalize the performance of the cylinders. This was found to be the case.

At the same time this test also allowed engine-based verification of the turbocharger run-up line for the 1-D code and also gave input to the choice of supercharger pulley ratio for the next-phase UB200 engine. The engine was operated using a target plenum pressure and temperature derived from the $1-D$ code and the results are shown in Figure 23. Here it can be seen that the engine achieved the full-load torque curve from $3000 \mathrm{rpm}$ onwards, giving $524 \mathrm{Nm}$ (386.4 lbft) and 382 bhp $(285 \mathrm{~kW})$ respectively. It had thus technically met both the maximum torque and power targets within Phase 2. EBP downstream of the turbine during this test was $33 \mathrm{kPa}$ at maximum power; while this may seem low, from previous work with the CAHU (for example during the fuels test described in [24]) the engine had not displayed any great sensitivity to EBP, although further tests are planned to be conducted in this area with the UB200 build specification.

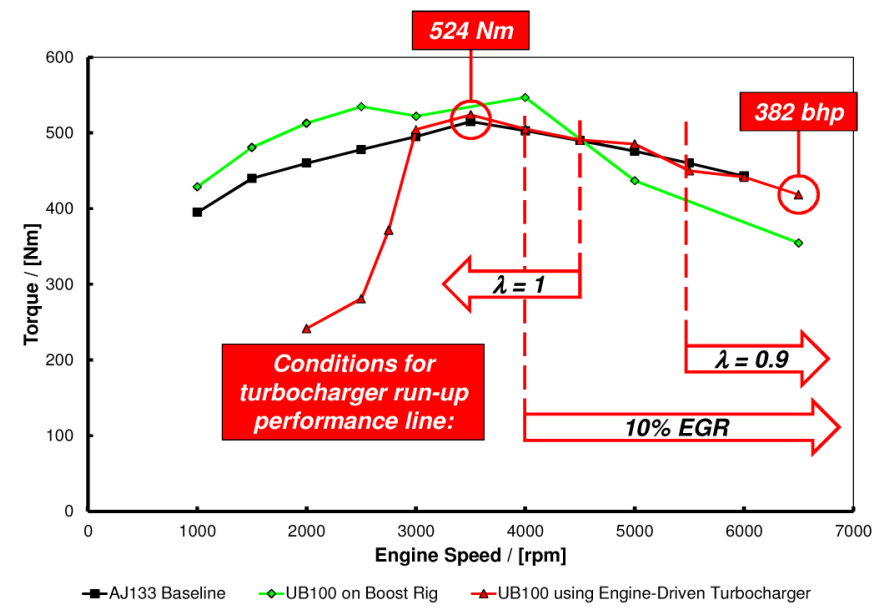

Fig. 23. UB100 engine performance with GT30 turbocharger and WCEM fitted versus the best results with the CAHU and log exhaust manifold fitted (see text for explanation). AFR and EGR conditions for the turbocharger test also shown

During this phase there was one instance of preignition which was not of the LSPI type. This occurred during the first tests of the engine with the WCEM fitted and when operating on the CAHU. For this test the twin-plug head was fitted, although the second under-port spark plug was not operational. As expected the WCEM permitted the removal of significant amounts of heat before the turbine (up to $53 \mathrm{~kW}$ having been measured on the water side), so the engine was progressively leaned-off from the previous levels of enrichment found to be necessary for the steel log-type manifold (but with no EGR being used). At this stage no limit was in place for exhaust port temperature and this rose to a high degree. It is believed that the exhaust valves then became extremely hot, raising their surface temperatures in the combustion chambers. The upshot was that the nonoperational plug overheated, forming a hot-spot for surface preignition, and an exhaust valve failed from a combination of the temperature and overpressure.

Fortunately this event did not cause a catastrophic failure for the cylinder head, which was recovered and was subsequently reused, but it did cause a review of safe exhaust port limits and how best to control TIT, balancing mixture enrichment with EGR rate.

To summarize the Phase 2 engine testing, the use of the CAHU and EGR pump rig coupled to the 1-D model proved extremely successful in decoupling combustion system development from any potential complications arising from attempting to control a complex charging system at the same time. It also proved the efficacy of increased charge cooling (in the constant density tests) and allowed systematic investigation of fuel properties and of catalyzed and uncatalyzed EGR (both to be reported elsewhere). It also permitted early reporting of achievement of the target power and torque outputs, which was an unplanned bonus arising out of a pragmatic approach to the testing. Thus at the end of this phase it was only necessary during Phase 3 to demonstrate the achievement of goals with the charging system operational, the core engine being unchanged and having been proved capable of delivering what the project required.

\section{Testing of the UB200 Engine during Phase 3}

For Phase 3, after commissioning at Lotus the UB200specification engine was shipped to the University of Bath and fitted to the test cell for running-in and testing, as shown in Figure 24. The status of the full-load performance at the official time of project completion is shown in Figure 25. In this figure, the data for the UB200 torque curve represents a combination of UB200 data up to $4750 \mathrm{rpm}$ and the turbocharger-only data from Figure 23 from 5000 rpm upwards. This situation was because of the fact that achievement of project torque and power targets had been demonstrated in Phase 2 (see previous section) and the measurement of part-load data at the points relevant for drive cycle operation was considered to be of overriding importance (see next section).

Immediately apparent in Figure 25 is a shortfall in low-speed torque. The early stages of testing had highlighted this area and a higher supercharger drive pulley ratio of 5.9:1 was procured and fitted for the data presented; the originallydelivered pulley ratio was lower than designed so this modification was merely correcting that state of affairs. However, the low-speed shortfall was also a function of the extremely steep turbocharger run-up line (itself apparent in the 
earlier tests shown in Figure 23); in the combined supercharger/turbocharger area of operation extremely fine control of wastegate and bypass had been found to be necessary because of the steepness of the run-up curve: boost overshoot was easily achieved.

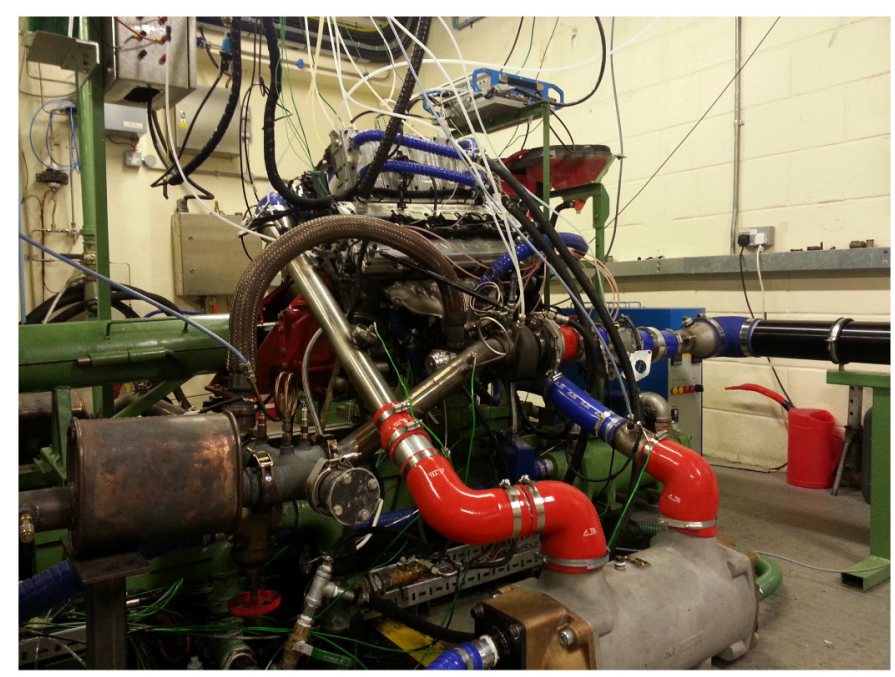

Fig 24. UB200 engine on the test cell at the University of Bath

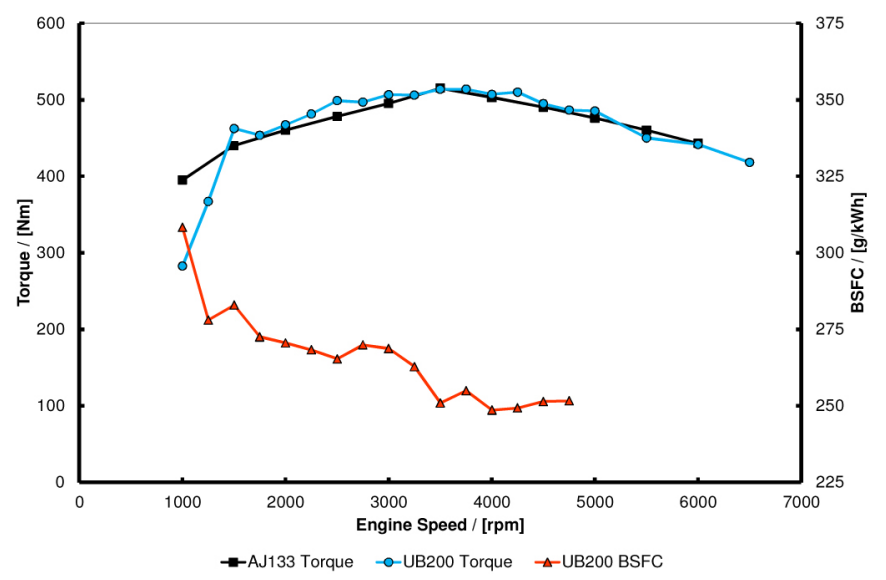

Fig. 25. UB200 full-load performance with 5.9:1 supercharger pulley ratio and $0.8 \mathrm{~A} / \mathrm{R}$ turbocharger turbine (see text for discussion)

It should also be pointed out that the large gas-wetted area and very high cooling capacity of the WCEM reduces preturbine temperature and enthalpy to a degree greater than would be expected of a fully-optimized IEM. This has been demonstrated by other researchers [30], where the turbocharger run-up line was delayed by $500 \mathrm{rpm}$, and in the Ultraboost application this will clearly have a detrimental effect given the observed sensitivity of the charging devices to each other's performance. It is believed that fitting a more-optimized IEM or a conventional steel component would significantly improve the situation at $1250 \mathrm{rpm}$ and below.

In order to improve the low-speed torque situation a turbocharger was procured with a smaller $A / R$ ratio for the turbine ( 0.67 versus 0.80 as tested to date) which, it was hoped, would enable the target curve to be met with a lesssevere build up in boost from the low-pressure stage. Again, this lower $A / R$ ratio was actually the one originally specified but which could not be supplied within the original timing required. Unfortunately this made the lack of achievement of low speed torque even worse. Subsequent investigations by Imperial College heating and pressurizing the air supplied to the R410 supercharger, as would be expected in a compound-charging system such as this, have shown some interesting effects with regard to the way the isentropic efficiency map of the supercharger changes as its inlet conditions alter. This phenomenon is the subject of further investigation which will be reported separately.

Thus the project had to report a slight miss in terms of achieving the low-speed torque curve. However, the success of the test work in Phase 2 in showing the ability of the core engine and combustion system to deliver the performance when fed with air from the CAHU and with representative boundary conditions does allow one very valid conclusion to be made: that in terms of extreme engine downsizing, the limit appears to be placed not by combustion but by air handling. Again, further work is planned in this area, since it was decided during the charging system specification process in Phase 2 to adopt a conservative approach to the choice of individual stage devices [20]. A more adventurous and new supercharging device will be tested as a high-pressure stage and the results reported separately.

Full-load BSFC data is also presented in Figure 25, for the full UB200 build only. The declining contribution of supercharger drive power is readily apparent, up to the point at which it is clutched out at $3250 \mathrm{rpm}$. This is due to the supercharger bypass being progressively opened as the required contribution from it to the overall charging system pressure ratio reduces. Generally, operating to a pre-turbine temperature of $900^{\circ} \mathrm{C}$ in the mid-range, the turbocharger-only portion of the BSFC curve was very good (at around $250 \mathrm{~g} / \mathrm{kWh}$ ), despite the high boost pressures demanded.

All of the low-speed data presented in Figure 25 was gathered at $\lambda=1$ with no cooled EGR being used up to $3500 \mathrm{rpm}$, the engine's knock tolerance and lack of LSPI as reported above still being present. At $1250 \mathrm{rpm}$ the engine was producing 367 $\mathrm{Nm}$, representing a BMEP of 23.1 bar. Between 3750 and 4000 $\mathrm{rpm} 8 \%$ cooled EGR was used and at $4250 \mathrm{rpm}$ and above this was $10 \%$. Since it was not found necessary to employ cooled EGR for knock suppression, at higher speeds it was introduced primarily as a means of reducing exhaust gas temperatures.

\section{UB200 Part-Load Fuel Economy Results}

Throughout the programme the 15 part load minimap points responsible for $99 \%$ of the fuel consumption on the NEDC were investigated in order to ascertain whether the project was on track to achieve the fuel consumption target. This was always felt to be the case, when compensating for the increased friction arising from using the AJ133 bottom end (this subject will be returned to in the Discussion later). Nevertheless, the only time when a full optimization and 
assessment could be carried out was when UB200 was on test, i.e. with the full self-driven charging system was fitted. These results are reported in Table 5, and include the reduction relative to the original AJ133 data.

Table 5. UB200 part-load fuel economy at 15 minimap points

\begin{tabular}{|c|c|c|c|c|}
\hline $\begin{array}{c}\text { Minimap } \\
\text { Point }\end{array}$ & $\begin{array}{c}\text { Engine } \\
\text { Speed } \\
(\mathrm{rpm})\end{array}$ & $\begin{array}{c}\text { Brake } \\
\text { Torque } \\
(\mathrm{Nm})\end{array}$ & $\begin{array}{c}\text { BSFC } \\
(\mathrm{g} / \mathrm{kWh})\end{array}$ & $\begin{array}{c}\text { BSFC } \\
\text { relative to } \\
\text { AJ133 } \\
(\%)\end{array}$ \\
\hline 1 & 600 & 27.9 & 482.4 & -35.0 \\
\hline 2 & 1500 & 39.8 & 355.1 & -29.0 \\
\hline 3 & 1500 & 104.2 & 257.7 & -13.7 \\
\hline 4 & 1500 & 198.9 & 248.1 & -0.3 \\
\hline 5 & 2000 & 79.6 & 275.2 & -18.8 \\
\hline 6 & 2000 & 198.6 & 239.3 & -4.4 \\
\hline 7 & 1250 & 15.9 & 614.5 & -38.1 \\
\hline 8 & 1000 & 15.9 & 612.9 & -36.8 \\
\hline 9 & 1000 & 79.6 & 278.5 & -17.2 \\
\hline 10 & 1250 & 159.2 & 246.7 & -6.1 \\
\hline 11 & 1350 & 238.7 & 260.5 & 6.4 \\
\hline 12 & 1500 & 298.4 & 273.9 & 14.7 \\
\hline 13 & 1250 & 119.4 & 254.5 & -10.7 \\
\hline 14 & 1250 & 59.7 & 294.6 & -24.7 \\
\hline 15 & 1500 & 139.3 & 247.4 & -8.4 \\
\hline
\end{tabular}

The data reported in Table 5 was in the final specification which gave the full-load results shown in Figure 25, i.e. with the 5.9:1 supercharger pulley ratio and the $0.80 \mathrm{~A} / \mathrm{R}$ turbocharger turbine.

Of these results point 7 has the biggest benefit (a reduction in BSFC of $38.1 \%$ ); it also has the highest residency in the NEDC drive cycle. It is followed by points 8,2 and 5 (improvements of $36.8 \%, 29.0 \%$ and $18.8 \%$, respectively). Points 11 and 12 are quite highly boosted, with a concomitantly large amount of supercharger work being required, and so represent a worsening of fuel consumption in comparison to the AJ133 benchmark. However, this is lower in magnitude than the benefits seen for the beneficial points $(6.4 \%$ and $14.7 \%$ increase in BSFC, respectively). Points 4 and 6 are also slightly boosted, but still represent a slight improvement $(0.3 \%$ and $4.4 \%$ ), indicating that the pumping, thermal and engine friction benefits associated with downsizing can offset extra work in the charging system at some loads. This will be discussed in more detail later.

Note that all of the data in Table 5 was gathered with the wastegate shut, implying that even lower fuel consumption could result with active control of it. However, in the discussions that follow, this is not taken into account.

When weighted for the NEDC in the project's fuel consumption tracking spreadsheet, and including all of the idle fuel consumption, the UB200 engine data presented in Table 5 yielded a warm engine fuel consumption improvement of $15.0 \%$ over the AJ133 baseline. In itself this is a significant improvement over the benchmark, because the AJ133 engine was designed with best BSFC in mind and also uses short cam profiles and wide-range phasing for throttling loss reduction via a degree of Miller-cycle operation [18].

During the project a full optimization of the idle condition could not be completed, so the idle fuel consumption value given in Table 5 (Point 1 ) is an assumed 35\% reduction over AJ133, this value being believed from general testing to be a conservative value. In terms of the weighted spreadsheet model, one of the biggest contributions to overall fuel consumption was found to be from this idle condition. Therefore applying start-stop technology would significantly improve the situation, and removing idle fuel usage in its entirety from the tracking spreadsheet (to provide a limit case for stop-start) increased the expected improvement to $23.0 \%$.

The continuing importance of idle fuel consumption is interesting because downsizing makes it a smaller proportion of the total fuel used in operation on the cycle (due to the reduction of throttling and friction). This fact is illustrated by the removal of the idle fuelling contribution from the equivalent data for the AJ133 baseline (which was recorded as part of the benchmarking during Phase 1 of the project as discussed above). This alone improved the NEDC fuel consumption of the AJ133-equipped benchmark vehicle by $12.3 \%$ (again, a limit case). Applying stop-start is therefore still an extremely beneficial move for the NEDC despite downsizing the engine by $60 \%$. A further observation, of course, is that friction is highly significant.

Directionally, therefore, since light-load conditions still have high residency on the drive cycle even with very highlydownsized engines such as this, on an engine level some means of dethrottling the engine further will be advantageous (in addition to stop-start technology). While several of the minimap point values gathered for Table 5 used the low-lift profiles, these represented a single discrete lift setting and not an optimized time-area solution for Miller cycle operation throughout the map. Future iterations of such engines would still be expected to benefit from continuously-variable valve lift, provided the impact on in-cylinder air motion and any friction demerit can be offset by pumping loss reduction. Such technology interactions have been shown to work on production engines, albeit with a much lower downsizing factor of about 33\% (e.g., a 3.0 litre NA engine being replaced with a 2.0 litre turbocharged one) [4]. Finally, it is interesting to note that in the case of automatic transmission utilization, because of the downspeeding these make possible in normal operation, on a vehicle system level some of the throttling loss reduction may not be realized; such are the trade-offs in powertrain system selection.

The improvement in fuel consumption presented in Table 5 is essentially that attributable to downsizing and the removal of a bank of cylinders only. Because of the adoption of the bottom end of the AJ133 engine, the Ultraboost engine was known to be carrying extra friction over that which would be expected from a fully-optimized clean-sheet engine design. Given the 
demonstrated importance of the light-load points on drive-cycle fuel economy, the effect of friction was investigated in more detail and this is discussed later.

\section{DISCUSSION}

\section{Ultraboost and the Rationale for Spark-Ignition Engine Downsizing}

As mentioned, downsizing is a megatrend in the automotive industry, realizing as it does several advantages over natural aspiration for the 4-stroke Otto cycle SI engine.

Thermodynamically, the advantages of downsizing stem chiefly from shifting the engine operating points to a higher level in its map, meaning that for any given drive torque the throttle is wider-open to the benefit of reduced pumping losses. At the same time, a significant effect is that the mechanical efficiency increases, this being defined as

$$
\eta_{\text {mech }}=\frac{\bar{p}_{\text {brake }}}{\bar{p}_{\text {ind }}}
$$

where $\eta_{\text {mech }}$ is the mechanical efficiency, $\bar{p}_{\text {brake is the brake }}$ mean effective pressure and $\bar{p}_{\text {ind }}$ is the gross IMEP [1].

Thermal losses are also reduced because of the reduction in absolute terms of the surface area of the combustion chambers. In the case of the Ultraboost engine design and the project baseline, the AJ133 V8, these were very significant savings, because as well as downsizing, significant downcylindering was also a key part of the project, and the Ultraboost cylinders themselves had significantly reduced swept volume. Table 6 shows data pertinent to this.

The combustion chamber surface area quoted in Table 6 does not include the crevice volumes, the importance of which is referred to separately below. In Table 6 it can be seen that although the smaller cylinders of Ultraboost have a lower CR, they actually had a $17.1 \%$ better surface area to volume ratio at top dead centre (TDC). This was due to the smaller swept volume being combined with the more undersquare bore:stroke ratio and the wider valve angles (the combustion chamber volume for Ultraboost being only $4.6 \%$ larger than AJ133). Furthermore, the effect of down-cylindering was that the total surface area exposed to combustion heat at TDC is a very significant $56.7 \%$ lower. As well as the mechanical efficiency effect already mentioned, this reduction in area through which to lose heat energy would have been a significant part of the downsizing advantages seen in the Ultraboost engine.

These effects have been investigated (albeit in engines rated to a significantly lower level) by Smith and Cheng [31], who also showed that top land crevice volume becomes disproportionately more important as engines are downsized. Among other factors, this is important with regard to fuel energy losses and also to NO release back into the combustion chamber during the exhaust stroke, NO being a known precursor for knock. For the two engines central to this project, Table 6 shows that AJ133 had a top land crevice volume per cylinder of $428 \mathrm{~mm}^{3}$, while that for Ultraboost was $370 \mathrm{~mm}^{3}$. Ultraboost therefore had significantly lower crevice volume expelling residual gas into a chamber ultimately containing roughly twice the charge air of AJ133 (because each cylinder has to produce twice the power output in the downsized engine). While it is accepted that this is a somewhat simplistic argument, it can be seen that under some circumstances extreme downsizing could yield benefits in this area, especially when the resulting gases are extremely well mixed by charge air motion and then compressed to a lower temperature by a reduced compression ratio.

Table 6. Surface area and volume information for the combustion chambers of the AJ133 and Ultraboost engines

\begin{tabular}{|l|l|l|l|}
\hline Parameter & AJ133 & Ultraboost & $\begin{array}{l}\text { Ultraboost } \\
\text { to AJ133 } \\
\text { Change (\%) }\end{array}$ \\
\hline $\begin{array}{l}\text { Compression } \\
\text { ratio (:1) }\end{array}$ & 11.5 & 9.0 & -21.7 \\
\hline $\begin{array}{l}\text { Combustion } \\
\text { chamber volume } \\
\text { per cylinder at } \\
\text { TDC }\left(\mathrm{cm}^{3}\right)\end{array}$ & 59.51 & 62.22 & 4.6 \\
\hline $\begin{array}{l}\text { Combustion } \\
\text { chamber surface } \\
\text { area per cylinder } \\
\left.\text { at TDC (mm }{ }^{2}\right)\end{array}$ & 16,077 & 13,934 & -13.3 \\
\hline $\begin{array}{l}\text { Surface area to } \\
\text { volume ratio at } \\
\text { TDC }\left(\mathrm{cm}^{-1}\right)\end{array}$ & 2.70 & 2.24 & -17.1 \\
\hline $\begin{array}{l}\text { Combustion } \\
\text { chamber surface }\end{array}$ & 128,616 & 55,736 & -56.7 \\
\hline $\begin{array}{l}\text { area for whole } \\
\text { engine at TDC } \\
\text { (mm }{ }^{2} \text { ) }\end{array}$ & & 370 & -13.6 \\
\hline $\begin{array}{l}\text { Top land crevice } \\
\text { volume per } \\
\text { cylinder (mm }\end{array}$ & 428
\end{tabular}

On the subject of CRs, it is argued that although thermodynamically irrefutable, chasing ever-higher values of this attribute may not always result in an optimum situation when allied to aggressive downsizing and down-cylindering. The Otto air standard cycle efficiency is given by:

$$
\eta_{\text {Otto }}=1-\frac{1}{r^{(\gamma-1)}}
$$

Eqn 3

where $\eta_{\text {Otto }}$ is the thermodynamic efficiency of the cycle and $r$ is the CR [1]. In Equation 3, assuming air for which the ratio of specific heats $\gamma$ is 1.4, the value of efficiency for the AJ133 NA CR of $11.5: 1$ is $62.35 \%$; for Ultraboost at $9: 1$ the value is 
$58.48 \%$. The relative reduction in Otto cycle efficiency is therefore $6.2 \%$. This assessment is based on the geometric CR only; valve timing will obviously effect this, as will ignition advance, which is particularly important in areas limited by knock. Against this observation then, given the much larger reductions in heat transfer area and potentially significantly lower friction of the downsized engine (see later), it can be appreciated that trading off some CR to enable extreme downsizing and down-cylindering could easily result in a more favourable fuel consumption situation.

One recent high-performance production engine bearing some similarity to Ultraboost in its capacity and PCP has been described recently [32]. Interestingly, this engine has an even lower CR than Ultraboost at 8.6:1, but nevertheless the vehicle in which it is fitted has good fuel consumption, with $\mathrm{CO}_{2}$ emissions of $161 \mathrm{gCO}_{2} / \mathrm{km}$ on the NEDC. This supports the contention that on an engine level, with a full optimization for extreme downsizing, a low CR does not necessarily have to result in poor efficiency.

Notwithstanding the above, given the excellent performance of the Ultraboost combustion system with regards to knock and preignition, it is intended to investigate compression ratio as part of a follow-on project; there is clearly some potential to improve fuel economy further by carefully raising this value. This testing will also include the effects of cooled EGR and more Miller-cycle-type operating strategies.

\section{Achievement of Ultraboost Engine Targets and the Current Limit of Extreme Spark-Ignition Engine Downsizing}

This has been an extremely successful project, producing a very reliable high-BMEP test engine which has permitted robust research into the current limiting factors for extreme SI engine downsizing. Project power and torque targets were met, and a significant improvement in drive-cycle fuel consumption has been shown to be achievable from the minimap points investigated. This last point was despite high engine friction levels, the effect of which will be discussed in a following section. In this light, the only minor shortfall in target achievement is the torque curve below $1500 \mathrm{rpm}$, as shown in Figure 25.

During Phase 2 the core engine was shown to be capable of producing the necessary torque to drive the supercharger and provide the $400 \mathrm{Nm}$ net torque target at $1000 \mathrm{rpm}$. The fact that when they were fitted to the engine the charging system components could not deliver this result does not detract from the success of the project, since one of its primary aims was to ascertain where the current limit for downsizing is.

Consequently the project has found that the air handling system is the area requiring new efforts to support further fuel economy improvements by this route.
Considering that the target torque curve is that of a naturallyaspirated engine, and the torque level demanded itself is very high, one could hypothesize that with a slight derate the charging system and engine combination as they are presently configured could replace an NA engine of approximately 4.5 litres. This would be the case if the curve was capped at the $1500 \mathrm{rpm}$ value of $460 \mathrm{Nm}$ until $5250 \mathrm{rpm}$. The existing 1500 rpm knee point would be at a normal engine speed for a typical downsized engine. Replacing a 4.5 litre engine with Ultraboost would represent a DF of $56 \%$.

The combustion system development has been an unqualified success. The engine has been routinely operated at over 550 $\mathrm{Nm}$ (35 bar BMEP) without issue. This suggests that if the charging system could be configured as successfully then DFs of over $70 \%$ may be achievable. Later projects will investigate this hypothesis. A later section will discuss the possible further benefits that might accrue in this case.

\section{The Effect of Base Engine Friction}

As discussed above, the measured improvement in fuel consumption is essentially that attributable to downsizing and down-cylindering by the removal of a bank of cylinders only. Because of the adoption of the bottom end of the AJ133 engine, the Ultraboost engine still had two high-pressure fuel pumps, a non-adjustable oil pump (with a flow rate sufficient for a larger-capacity V8) and a mechanical water pump with clearly excess capacity. Since the Ultraboost engine used four $D I$ injectors from an engine with similar power output per cylinder as the supercharged AJ133 engine, without the need to resort to supplemental PFI fuelling, there is an argument to say that just one respecified high-pressure pump would suffice. Furthermore, in order to use the fast-acting camshaft phasers from the AJ133, as mentioned it also had 'thumper' cams to provide a non-uniform driving torque for the phasers, and these would also have increased friction. The AJ133 bottom end also has an extra jackshaft for its oil and high-pressure fuel pumps, whose friction is therefore shared between a smaller number of cylinders in Ultraboost. Finally, due to its V8 parentage the engine had no crankshaft désaxé (or offset), which reduces piston thrust forces, is common in modern single-bank automotive engines and is very important when high cylinder pressures are generated, as is the case here.

Because of these factors, the effect of friction was investigated in detail.

\section{Motored Friction Data}

In order to assess the differences between the target fuel consumption benefit and the achieved measured and spreadsheet-estimated benefit of $15.0 \%$ compared with the AJ133 NA V8 baseline at the same speeds and torques, data for motored friction under warm operation (with the engine coolant and oil temperatures at $90^{\circ} \mathrm{C}$ ) was taken at the University of Bath. This was a measure of the engine friction only (i.e. pumping work was excluded) and was collected at 
$500 \mathrm{rpm}$ intervals between 1000 and $6500 \mathrm{rpm}$. This data is compared with that of typical downsized gasoline engines from the FEV scatter bands in Figure 26, indicating the region in which a production engine friction mean effective pressure (FMEP) value should typically $b^{2}$.

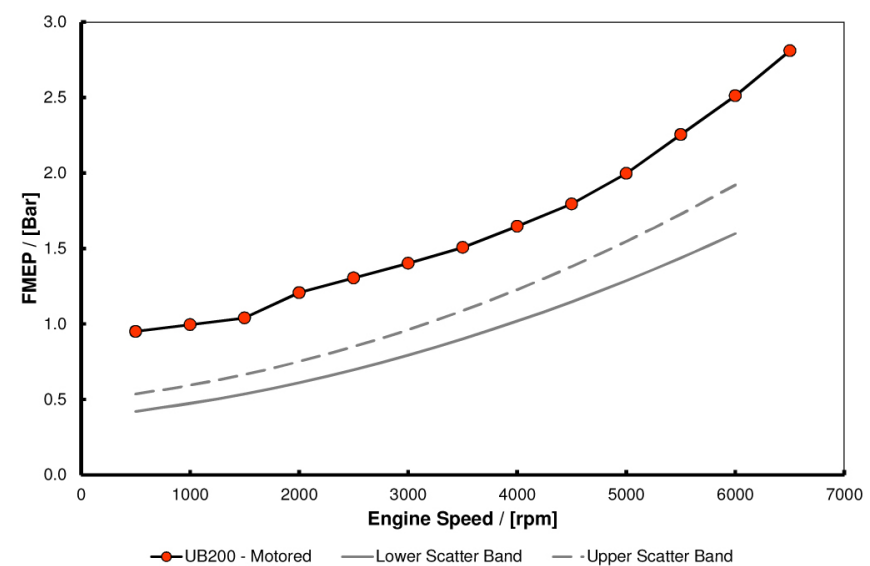

Fig. 26. Measured UB200 engine friction versus FEV scatter band data for typical turbocharged DISI engines

Immediately apparent from Figure 26 is the high level of engine friction in Ultraboost, as surmised above. One fact to emerge from this is that although the project target was to achieve the peak torque and power targets from the engine as built and tested, walking the friction back to the mid-point in the scatter band at the related peak engine speeds of 3500 and $6500 \mathrm{rpm}$ respectively suggests that a production engine would be generating approximately 0.5 and 1.1 bar more BMEP at these conditions. These are increases of $8 \mathrm{Nm}$ and $12 \mathrm{~kW}$ (16 bhp) respectively, which, added to the measured outputs, implies corrected Ultraboost performance of $532 \mathrm{Nm}$ (392 lbft) and 398 bhp $(297 \mathrm{~kW})$ at the respective maxima.

\section{Fuel Map Manipulation}

Since the UB200 FMEP was above the FEV scatter band a simulated improvement to the fuel consumption at the minimap data points was performed. This was done to bring the UB200 friction in line with what JLR believe the friction values for a future state-of-the-art 4-cylinder downsized engine of this capacity and type will be, and thus to show the potential fuel consumption improvement using a specifically-designed 4-cylinder base engine, rather than the V8 donor.

The method by which this was done was via torque shifting. This is implemented by assuming that the engine is maintaining an IMEP value, and therefore any reductions in FMEP inherently lead to gains in BMEP, because

$$
\mathrm{IMEP}_{\text {net }}=\mathrm{BMEP}+\mathrm{FMEP} .
$$

2. Note that the data for the FEV scatter bands has been extrapolated below $1000 \mathrm{rpm}$, in order to compare it to the Ultraboost data in the fuel economy discussion in the text.
Since this alters the BMEP set points of the fuel map, interpolation was used to produce a new fuel-flow map against the original set points. Figure 27 gives a schematic representation of this process using arbitrary fuel flow values.

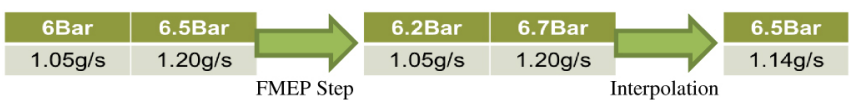

Fig. 27. Diagrammatic representation of fuel map manipulation for a 0.2 bar FMEP reduction

The fuel flow data from the University of Bath was captured at the 15 minimap points over the NEDC cycle; however, in order to implement this torque shifting strategy, a full fuel map was required. Because only the 15 minimap points were available, the remainder of the map required for the analysis was generated through interpolation. To provide more robustness, it should be noted that at the specific points, the original minimap data was used to override the data from interpolation, as the errors were sufficiently small for this approach to be deemed valid.

The fuel flow values produced from the torque shifting method at the minimap points were then extracted from the newlygenerated fuel map and NEDC fuel usage was calculated (using the NEDC weightings for each minimap point). Because the AJ133 NA and UB200 measured datasets both had an idle speed of $600 \mathrm{rpm}$, it should also be noted that for the fuel flow data generated by this process, the continued importance of the idle operating point was investigated by increasing it from 600 to $680 \mathrm{rpm}$ for Ultraboost, this being considered more appropriate for a 4-cylinder engine. Also investigated was the frictional effect of second-order balance shafts. The result of this walk are shown in Table 7.

Table 7. Percentage improvement in fuel consumption results for Ultraboost versus AJ133 NA after friction adjustment

\begin{tabular}{|c|c|c|}
\cline { 2 - 3 } \multicolumn{1}{c|}{} & $\begin{array}{c}\text { Without Second } \\
\text { Order Balancing }\end{array}$ & $\begin{array}{c}\text { With Second } \\
\text { Order Balancing }\end{array}$ \\
\hline $600 \mathrm{rpm}$ Idle & $23.8 \%$ & $23.6 \%$ \\
\hline $680 \mathrm{rpm}$ Idle & $22.8 \%$ & $22.6 \%$ \\
\hline
\end{tabular}

The original programme assumptions indicated that, of the target $35 \%$ fuel consumption benefit, $23 \%$ would have to be provided by an engine with a DF of $60 \%$ (when calculated at warm conditions), with the remaining $12 \%$ coming from the vehicle. In Table 7 it can be seen that, with friction adjusted to be representative of modern levels, the project has met its target of a $23 \%$ improvement in fuel economy from the engine alone, not including the use of stop-start technology. A further interesting finding is that increasing the idle speed by only a small amount reduces the improvement by $1 \%$; this effect is, of course, reduced by the application of stop-start technology in a vehicle.

From the data in Table 7, balance shafts do not seem to increase fuel consumption significantly. Recent work by others shows that second-order balancing can be deleted in very-high specific output 4-cylinder engines if other measures are taken [32]; however, this was for a specific application and, in an 
engine which may have to be installed in several platforms, provision of balance shafts may be the only sensible solution. Conversely, in the engine in reference [32], a very high output was achieved and the provision of high-specification pistons capable of resisting combustion pressures of the same order as in Ultraboost could easily result in lighter components. Therefore the necessary increase in piece price forced by cylinder pressure issues could easily result in the welcome secondary benefit of the possibility of removing second-order balance shafts.

How the warm-engine results discussed above relate to the overall project target of $35 \%$ improvement over the baseline 2010 MY Range Rover is returned to in the next section.

\section{Results of Full Vehicle Simulation}

In order to provide a realistic dataset, the fuel consumption map for the case with 680 rpm idle speed and full second-order balancing was fully modelled using the proprietary vehicle fuel consumption code CalSim.

The overall improvement target of 35\% from the Ultraboost project included some vehicle technology improvements that would be implemented within the project timeframe. In order to validate these additional benefits, a full vehicle simulation of a 2013 MY Range Rover with the Ultraboost engine installed (with the data set for state-of-the-art 4-cylinder friction) was conducted, with the results being compared with the baseline 2010 MY vehicle fitted with the AJ133 NA V8 using the certified figures. This simulation was performed using the proprietary CalSim software package, with various vehicle developments that had been validated as part of the 2013 MY vehicle programme ${ }^{3}$.

Since any production version of Ultraboost would be a state-ofthe-art engine, it was reasonable to assume that the engine would have advanced technologies to deliver a fast engine warm-up characteristic. The warm-up characteristic for this engine was developed using technologies from an advanced 4-cylinder engine that would deliver an extremely fast engine warm-up time (i.e. water temperature at $95^{\circ} \mathrm{C}$ within 500 seconds on the NEDC cycle); the use of an IEM would be expected to be a contributor to this. The oil would also be expected to warm up very quickly. The engine fluid temperature profiles used for the analysis over the NEDC and FTP-75 cycles are shown in Figures 28 and $\underline{29}$ respectively.

The fast warm-up strategy was found to reduce the $\mathrm{CO}_{2}$ emissions on the NEDC by an additional $1.5 \%$ compared with a typical warm-up profile from a current production 4-cylinder engine.

3. The first step in the modelling of Ultraboost in the $2013 \mathrm{MY}$ vehicle did provide a means of comparison with a production vehicle, because the AJ133 NA engine was offered in this vehicle in some markets. The accuracy of modelling was within $1 \%$ of the certified $\mathrm{CO}_{2}$ emissions figure for this vehicle specification on the NEDC cycle, providing confidence in both the model and the process adopted. From this level, stop-start and the Ultraboost engine were then applied in discrete steps.

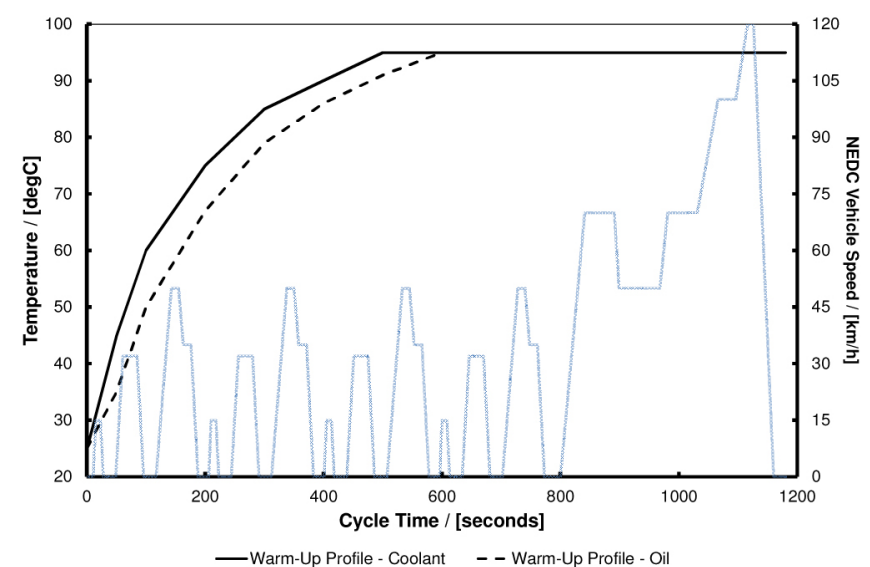

Fig. 28. Engine fluid temperatures during NEDC Cycle

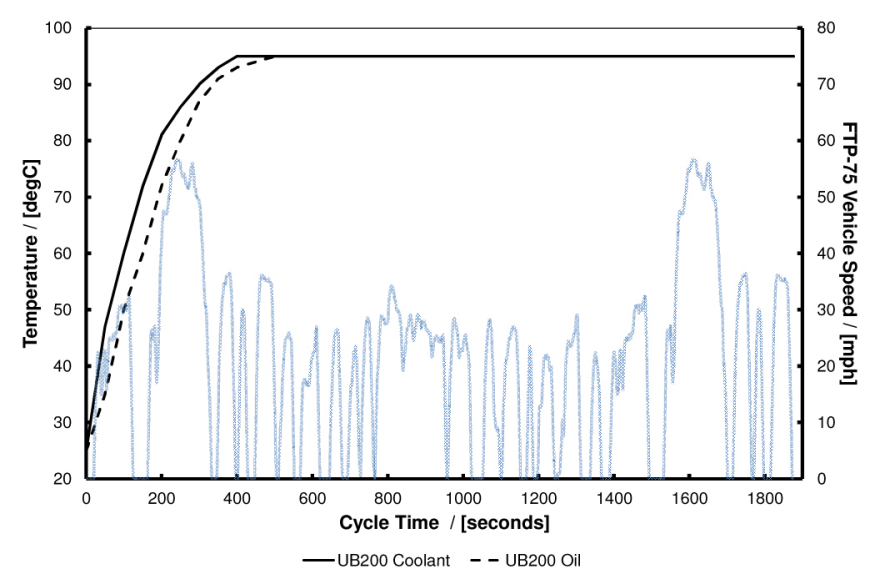

Fig. 29. Engine fluid temperatures during FTP-75 Cycle

The results from the CalSim study with the new fast warm-up schedule can be seen in Tables $8, \underline{9}$ and $\underline{10}$ for the NEDC cycle, FTP-75 cycle and a constant $120 \mathrm{~km} / \mathrm{h}$ cruise, respectively. The vehicle changes from 2010 to 2013 MY include a $420 \mathrm{~kg}$ mass reduction, an 8-speed gearbox with increased ratio spread, and various aerodynamic drag and rolling resistance reduction measures. As a consequence, the improvements solely due to the vehicle changes are shown, together with that due to the stop-start system and finally that due to the engine itself.

Table 8. Overall vehicle implementation improvements over the 2010 MY baseline vehicle on the NEDC cycle

\begin{tabular}{|l|c|}
\cline { 2 - 2 } \multicolumn{1}{c|}{} & \multicolumn{1}{c|}{$\begin{array}{c}\text { NEDC } \\
\text { CO2 Delta } \\
(\boldsymbol{\%})\end{array}$} \\
\hline $\begin{array}{l}\text { 2013 MY } \\
\text { Range Rover } \\
\text { with AJ133 } \\
\text { NA V8 }\end{array}$ & 8.3 \\
\hline Stop-start & 7.6 \\
\hline UB200 & 21.0 \\
\hline Total & $\mathbf{3 6 . 9}$ \\
\hline
\end{tabular}


Table 9. Overall vehicle implementation improvements over the 2010 MY baseline vehicle on the FTP-75 and Metro Highway cycles

\begin{tabular}{|l|c|c|c|}
\cline { 2 - 4 } \multicolumn{1}{c|}{} & \multicolumn{1}{c|}{ FTP-75 } & $\begin{array}{c}\text { Metro } \\
\text { Highway } \\
\text { mpUSg } \\
\text { mpUSg } \\
\text { Delta (\%) }\end{array}$ & $\begin{array}{c}\text { Combined } \\
\text { Delta (\%) }\end{array}$ \\
\begin{tabular}{|l} 
mpUSg \\
Delta (\%)
\end{tabular} \\
\hline $\begin{array}{l}\text { 2013 MY } \\
\text { Range Rover } \\
\text { with AJ133 } \\
\text { NA V8 }\end{array}$ & 11.3 & 7.8 & 10.1 \\
\hline Stop-start & 8.2 & 0.0 & \\
\hline UB200 & 35.4 & 21.7 & 30.1 \\
\hline Total & $\mathbf{5 4 . 9}$ & $\mathbf{2 9 . 5}$ & $\mathbf{4 5 . 4}$ \\
\hline
\end{tabular}

Table 10. Overall vehicle implementation improvements over the 2010 MY baseline vehicle during a $120 \mathrm{~km} / \mathrm{h}$ cruise

\begin{tabular}{|l|c|c|}
\cline { 2 - 3 } \multicolumn{1}{c|}{} & $\begin{array}{c}\text { 120kph } \\
\text { Cruise } \\
\text { 1/100km } \\
\text { Delta (\%) }\end{array}$ & $\begin{array}{c}\text { 120kph } \\
\text { Cruise } \\
\text { mpg Delta } \\
(\%)\end{array}$ \\
\hline 2013 MY & 18.4 & 22.6 \\
\hline $\begin{array}{l}\text { Range Rover } \\
\text { with AJ133 } \\
\text { NA V8 }\end{array}$ & & \\
\hline Stop-start & 0.0 & 0.0 \\
\hline UB200 & 6.1 & 9.9 \\
\hline Total & $\mathbf{2 4 . 5}$ & $\mathbf{3 2 . 5}$ \\
\hline
\end{tabular}

From the data presented in Table 8 it can be seen that the engine together with the stop-start system delivers a $28.6 \%$ improvement in $\mathrm{CO}_{2}$ emissions on the NEDC cycle. In absolute terms, the engine alone delivers $21 \%$ of this benefit, the reduction versus the $23 \%$ being targetted on the fuel consumption monitor spreadsheet being due to the stop-start technology benefit overriding the minimap point that yielded the largest improvement to the fuel consumption (i.e., idle), as well as to the increased friction due to the cold-start operation. However, factoring in the benefit achieved through the vehicle platform change yields an overall improvement in $\mathrm{CO}_{2}$ of $36.9 \%$ on the NEDC cycle. The project has thus exceeded the vehicle-level fuel consumption improvement target.

One surprising result is the magnitude of the improvement on the FTP-75 and Metro Highway cycles, showing that the engine configuration is also valid for US driving styles. A discussion of the reasons for the relative magnitudes of the individual contributions is given in the Appendix. The magnitude of the improvement for the $120 \mathrm{kph}$ cruise is similarly gratifying; a $9.9 \%$ improvement in fuel economy solely from the engine at this condition shows the benefit of retaining good fuel economy throughout the map, because the Range Rover vehicle has a large frontal area and so the engine will be at quite a high load at this cruise condition. Because it reduces part load losses, downsizing generally shows better results in vehicles with low mass and drag where operation at light load is more frequent; as a consequence it is intended to model the engine in a passenger car application and to report on this in a later publication, since such a vehicle was not the target for this project.

\section{The Future Potential of Downsizing}

Versus other downsized production engines, Ultraboost does not contain any components or concepts which are presently not in large-scale production on SI engines, except for the cooled EGR system and its associated EMS control. Such systems exist on light-duty diesel engines and thus it is not believed that the adoption of these on future production gasoline engines is in any way ruled out. The only other significant extra components over a typical turbocharged DISI engine are the high-pressure supercharger, its associated bypass arrangement, and the inter-stage chargecooler. Indeed, the last of these could possibly be avoided if the remaining chargecooler was enlarged to suit and the temperatures associated with the high-pressure supercharger were within safe metallurgical limits. Thus, if the anticipated further benefit of yet more downsizing was significant enough, furtherenhanced cost-benefit advantages could be anticipated.

McAllister and Buckley [15] investigated the potential of downsizing with validation data from earlier work that was used to help set the direction for Ultraboost. Assuming that the shortfall in low-speed boost could be addressed by new technologies currently in development but outside the scope of this project, and that the combustion system can support even higher levels of BMEP, it is believed that the future potential of downsizing can be inferred from the results published in [15] and reproduced here as Figure 30.

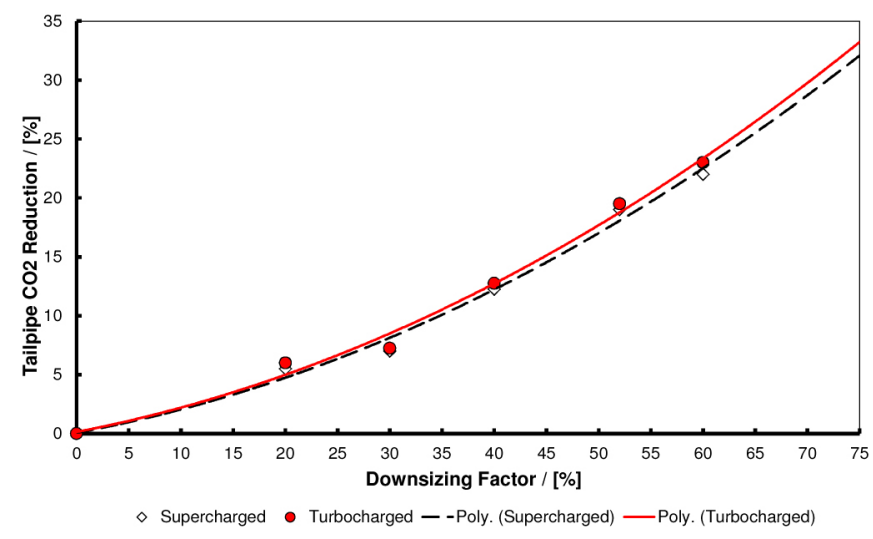

Fig. 30. Data published by McAllister and Buckley and used in the original sizing assessments for achieving a $23 \%$ reduction in fuel consumption from Ultraboost (data taken from Figure 7 of [15])

The data in Figure 30 was all obtained using warm engine conditions as per the spreadsheet comparison method used in the Ultraboost project. While it is accepted that the exponential shape of the lines in the figure cannot continue indefinitely, the data does suggest some further possibility with respect to downsizing and fuel consumption improvement. In Figure 30 the trendlines of McAllister and Buckley have been extended to $75 \%$ capacity reduction and suggest that for a DF of $65 \%$, a 
$26 \%$ improvement in $\mathrm{CO}_{2}$ could be expected. If the line does not turn over, for DFs of $70 \%$ and $75 \%$ the equivalent reductions could be expected to be $29 \%$ and nearly $33 \%$ respectively. Relative to the $23 \%$ shown to be achievable by Ultraboost, these are absolute potential improvements of 3,6 and $10 \%$, just by evolving existing technology bundles (assuming that the necessary charging systems can be developed to achieve the $60 \%$ DF of Ultraboost). The improvements from the vehicle side could be expected to be additive, and possibly even greater if the engine is lighter than any large NA engine being replaced. Therefore, it may be considered worthwhile investigating swept volumes in the region of 1.5 litres to replace 5.0 litre NA engines (i.e. a DF of $70 \%$ ).

This latter observation brings into question the minimum acceptable number of cylinders for extreme downsizing. The limit could eventually be set by the sheer magnitude and increased spacing of the combustion events with a reduced numbers of cylinders, especially if surface area-to-volume or other considerations force a minimum practical cylinder swept volume. At the Ultraboost level of extreme downsizing, in most cases the resulting engine is by default going to be very powerful if such minimum cylinder number and size criteria arise. It could be that this itself provides the pragmatic limit to the approach, and that other dethrottling or hybridization technologies will then have to be developed in order to improve vehicle fuel economy further.

From the targets actually met and the configuration built, the present limitation to extreme engine downsizing appears to be in air handling. New technologies are being investigated within the industry such as parallel- and series-sequential systems utilizing unusual engine-based solutions [33] or extensive use of cooled aluminium to reduce fuel enrichment [34], but none operates at the BMEP level over such a wide engine speed range as Ultraboost. It may be possible that recent advances in diesel charging systems might be transferable to the task [35], but such solutions might be expected to be expensive given the requirement for high-temperature steels forced by gasoline exhaust temperatures. Furthermore, with the charging system configuration tested here, there will be increased supercharger work at mid-loads due to the high bypass flow necessary; if this could be reduced with a more-advanced system then fuel economy at the relevant points could be expected to improve further. Thus the opportunity has been created for new developments to be applied, and these will be the subject of further research using the Ultraboost platform.

\section{Ultraboost Test Engine Reliability}

During testing, considering its prototype nature and the very high loading that it has been subjected to, the Ultraboost engine was extremely reliable. During Phase 2 the total running time was 410.4 hours with the time spent on test above 20 bar BMEP being 121 hours. For Phase 3, the values were 107 and 13 hours respectively.
The first two builds of UB100 were restricted to a total of 80 hours each in order to assess the condition of the engine by tear-down inspection. There were instances of porous castings which required action, and some rebuilds were required due to increasing blowby, but there were no catastrophic engine failures, the only major one being the surface preignition/valve head failure already mentioned. The blowby increase is understandable given that PCPs of 145 bar were routinely seen and that the piston contained no countermeasures to this other than being made of extremely good aluminium alloy material. At the end of the project, some metal matrix composite pistons were procured, but these were not tested within the project. In any production application, such an approach to material selection could be taken, or perhaps a steel ring carrier or even a steel piston could be used. In the production engine described in [32], which has cylinder pressures comparable to those seen in Ultraboost, a motor sport alloy is reported to have been used, implying that a ready engineering solution exists.

Compressor blade erosion is one area which will require further investigation if low-pressure EGR systems are to be developed to production in the future. Figure 31 shows the condition of the compressor of the GT30 A/R 0.80 turbine turbocharger at the end of Phase 3 testing. It should be noted that EGR had not been used during all of this phase. Clearly evident is damage to the edges of the blades. However, in mitigation, the desired EGR temperature could not be achieved with engine coolant, and so test cell process water at $25^{\circ} \mathrm{C}$ was used in the cooler, undoubtedly causing condensation of water in the EGR stream. From the industry's experience of low-pressure EGR on light-duty diesel engines, more careful optimization of the system would be expected to improve or remove this issue entirely.

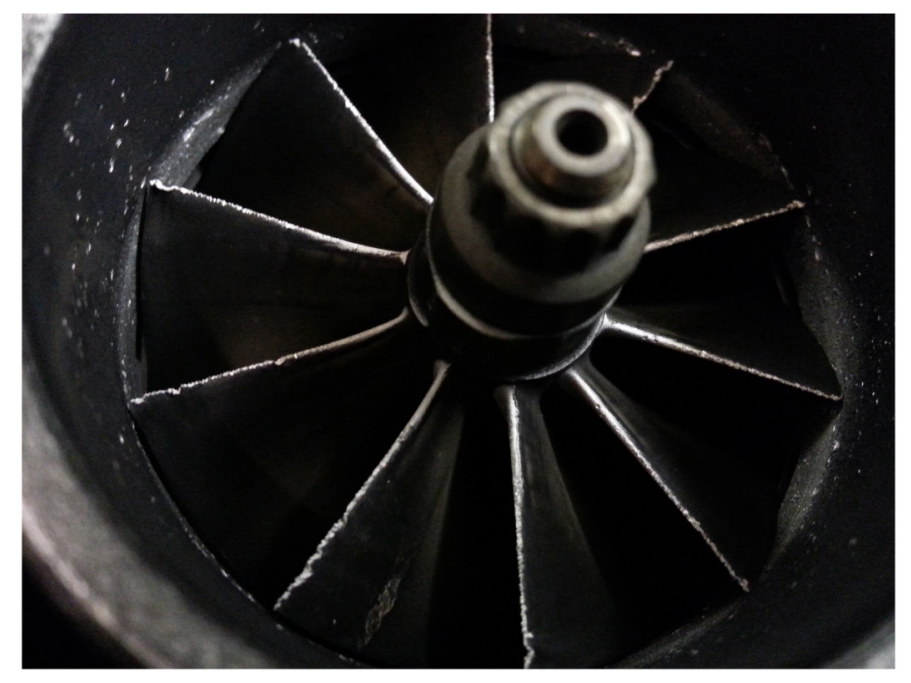

Fig. 31. Turbocharger compressor blade erosion found at the end of testing during Phase 3

Alternatively, adoption of a high-pressure EGR system (possible on this engine because of its lack of requirement for EGR before the boost crossover point) would also remove the 
issue. High-pressure EGR would, of course, also allow faster control of the system, making it easier to apply during transients and at light loads. Linking an investigation of EGR routes to a study of catalyzed and uncatalyzed EGR would therefore seem worthwhile; Lewis et al. present some initial findings on this subject in [23].

In view of its excellent reliability in the face of continual operation at up to 35 bar, it is intended to use the Ultraboost engine for follow-on projects to investigate the potential of further downsizing beyond a DF of $60 \%$.

\section{SUMMARY/CONCLUSIONS}

Ultra Boost for Economy was a collaborative project partfunded by the Technology Strategy Board, the UK's innovation agency, which was initiated to investigate the present limits on extreme downsizing and down-cylindering using a large naturally-aspirated engine as a baseline. The chosen baseline engine, the Jaguar Land Rover AJ133 5.0 litre V8, already employed several technologies to provide reduced fuel consumption, such as cam profile switching and reduced high-pressure oil demand through the adoption of novel camshaft phasing technology.

The following conclusions are drawn from the work conducted and reported here:

1. The results of the project show that it is possible to provide improved fuel consumption on the order of $23 \%$ (under warm conditions) at a downsizing factor of $60 \%$ compared to the chosen baseline, adhering to the expected trends from earlier analysis.

2. The combustion system proved extremely knock- and preignition-resistant, itself helping to deliver the excellent fuel consumption results. Using a dedicated facilitated combustion air handling unit (CAHU) it was easily operated at the very high BMEPs in order to deliver the engine-level performance when a representative set of charging system boundary conditions were applied.

3. A bespoke EGR supply unit was also developed and applied in order to facilitate cooled EGR application to the engine when the CAHU was being used. This will be used for further related EGR studies later on.

4. An intake port which simultaneously possessed very high tumble and flow was developed for the project. The ability of this port to provide sufficient air flow to achieve the fullload targets while providing very high in-cylinder activity to fully homogenize the mixture is believed to be central to the excellent performance of the combustion system.

5. The test fuel used to supply all results in this paper was a market 95 RON specification fuel. Using the CAHU a large matrix of fuel tests was also performed and this will be reported elsewhere, but these did reinforce the impressive knock limit of the combustion system.
6. An advanced charging system was developed in parallel to the base engine tests with the CAHU. This was fitted to the core engine and tested in the final phase of the project. This charging system was found to be capable of supplying sufficient air to achieve the target torque curve above 1500 rpm, being that of of the baseline AJ133 engine.

7. With the engine-driven turbocharger fitted the torque and power maxima achieved were $524 \mathrm{Nm}$ (386.4 lbft) and 382 bhp $(285 \mathrm{~kW})$ respectively.

8. An investigation into surface areas and volumes in the combustion chamber showed some possible reasons for the improvement in fuel consumption despite a relatively low compression ratio of 9:1 being adopted.

9. Friction was found to be very significant in the delivery of part-load fuel consumption. Only when compensation was made for the high base engine friction (itself an artifact of the decision to base the test engine on the AJ133 bottom end) were the fuel consumption targets achieved.

10. Applying the friction correction to the full-load results implies adjusted performance maxima of $534 \mathrm{Nm}$ (394 lbft) and 398 bhp (297 kW).

11. The engine has been extremely reliable and during development testing has routinely been operated at over $550 \mathrm{Nm}$ (35 bar BMEP) without issue.

12. On a vehicle level, modelling showed that the project target of a reduction in tailpipe $\mathrm{CO}_{2}$ of $35 \%$ is possible, assuming friction is at a reasonable level and with various technologies used which have already been applied to the production vehicle.

13. As a consequence of the work performed within the project it is contested that the current limit to extreme downsizing using regular pump gasoline is not the combustion system. Instead, the charging system is the weak link and further efforts will have to be made in order to provide greater levels of downsizing to yield more fuel economy from a practical development direction.

14. A pragmatic limit could be the trade-off in power output, number and size of cylinders and combustion chamber geometry. This is worthy of further investigation.

15. Compressor blade erosion is one aspect of cooled EGR system development which will need to be investigated further.

This has been a very successful project. As a consequence, the developed engine and facility will be used for further investigations into the potential of further downsizing, cooled EGR, fuel characteristics and advanced charging system components and concepts.

\section{REFERENCES}

1. Heywood, J.B., "Internal Combustion Engine Fundamentals", McGraw-Hill Book Company, New York, USA, 1988, ISBN 0-07100499-8. 
2. Osborne, R., Stokes, J., Ceccarini, D., Jackson, N., Lake, T., Joyce, M., Visser, S., Miche, N., Begg, S., Heikal, M., Kalian, N., Zhao, $H$. and Ma, T., "The 2/4SIGHT Project - Development of a Multi-Cylinder Two-Stroke/Four-Stroke Switching Gasoline Engine", JSAE paper number 20085400 and JSAE 2008 Proceedings No. 79-08, pp. 11-16, ISSN 0919-1364, JSAE 2008 Congress, Yokohama, Japan, 21st-23rd May, 2008.

3. Turner, J.W.G. and Pearson R.J., "The turbocharged directinjection spark-ignition engine", in Zhao H. (ed.), Direct injection combustion engines for automotive applications: Science and technology. Part 1: spark-ignition engines, Woodhead Publishing Limited, Cambridge CB21 6AH, UK, 2009, ISBN 1-84569-389-2.

4. Steinparzer, F., Unger, H., Brüner, T. and Kannenberg, D., "The new BMW 2.0 litre 4-cylinder S.I. engine with Twin Power Turbo Technology", $32^{\text {nd }}$ Vienna Motor Symposium, Vienna, Austria, $5^{\text {th }}$ $6^{\text {th }}$ May, 2011.

5. Steinparzer, F., Klüting, M. and Poggel, J., "The new BMW V8 Powertrains: Customer Value through Turbocharging and Fully Variable Valvetrain", $33^{\text {rd }}$ International Vienna Motor Symposium, Book 1 pp. 72-84, Vienna, Austria, 26 $6^{\text {th }}-27^{\text {th }}$ April, 2012.

6. Borrman, D., Kuhlbach, K., Friedfeldt, R., Mehring, J. and Fritsche, R., "Cylinder Head Integrated Exhaust Manifold IEM Applied for Gasoline Downsizing Concepts", $17^{\text {th }}$ Aachen Colloquium, pp. 1001-1017, Aachen, Germany, $6^{\text {th }}-8^{\text {th }}$ October, 2008.

7. Helduk, T., Dornhöfer, R., Eiser, A., Grigo, M., Pelzer, A. and Wurms, R., "The new generation of the R4 TFSI engine from Audi", $32^{\text {nd }}$ Vienna Motor Symposium, Vienna, Austria, $5^{\text {th }}-6^{\text {th }}$ May, 2011.

8. Ernst, R., Friedfeldt, R., Lamb, S., Lloyd-Thomas, D., Phlips, P., Russell, R. and Zenner, T., "The New 3 Cylinder 1.0L Gasoline Direct Injection Turbo Engine from Ford", $20^{\text {th }}$ Aachen Colloquium, pp. 53-72, Aachen, Germany, 11-12th October, 2011.

9. Coltman, D., Turner, J., Curtis, R., Blake, D. et al., "Project Sabre: A Close-Spaced Direct Injection 3-Cylinder Engine with Synergistic Technologies to Achieve Low CO2 Output," SAE Int. J. Engines 1(1):129-146, 2008, doi:10.4271/2008-01-0138.

10. Krebs, R., Szengel, R., Middendorf, H., Fleiß, M., Laumann, A. and Voeltz, S., "The New Dual-Charged FSI Petrol Engine by Volkswagen Part 1: Design", MTZ 11/2005, Volume 66, pp. 2-7, November 2005.

11. Möller, C., Johansson, P., Grandin, B., and Lindström, F., "Divided Exhaust Period - A Gas Exchange System for Turbocharged SI Engines," SAE Technical Paper 2005-01-1150, 2005, doi:10.4271/2005-01-1150.

12. Roth, D., Keller, P., and Sisson, J., "Valve-Event Modulated Boost System," SAE Technical Paper 2010-01-1222, 2010, doi:10.4271/2010-01-1222.

13. Hu, B., Akehurst, S., Brace, C., Copeland, C. et al., "1-D Simulation Study of Divided Exhaust Period for a Highly Downsized Turbocharged SI Engine - Scavenge Valve Optimization," SAE Int. J. Engines 7(3):in press, 2014, doi:10.4271/2014-01-1656.

14. Krebs, R., Szengel, R., Middendorf, H., Sperling, H., Siebert, W., Theobald, J. and Michels, K., "The New Dual-Charged FSI Petrol Engine by Volkswagen Part 2: Thermodynamics", MTZ 12/2005, Volume 66, pp. 23-26, December 2005.

15. McAllister, M.J. and Buckley D.J., "Future gasoline engine downsizing technologies - $\mathrm{CO}_{2}$ improvements and engine design considerations", paper number C684/018, pp. 19-26, Institution of Mechanical Engineers Internal Combustion Engines Conference, London, UK, $8^{\text {th }}-9^{\text {th }}$ December, 2009.

16. Hancock, D., Fraser, N., Jeremy, M., Sykes, R. et al., "A New 3 Cylinder 1.21 Advanced Downsizing Technology Demonstrator Engine," SAE Technical Paper 2008-01-0611, 2008, doi:10.4271/2008-01-0611.

17. Salamon, C., McAllister, M., Robinson, R., Richardson, S., Martinez-Botas, R., Romagnoli, A., Copeland, C. and Turner J.W.G., "Improving Fuel Economy by $35 \%$ through combined Turbo and Supercharging on a Spark Ignition Engine", $21^{\text {st }}$ Aachen Colloquium, pp. 1317-1346, Aachen, Germany, $8^{\text {th }}-10^{\text {th }}$ October, 2012.

18. Sandford, M., Page, G., and Crawford, P., "The All New AJV8," SAE Technical Paper 2009-01-1060, 2009, doi:10.4271/2009-011060 .

19. Wurms, R., Budack, R., Böhme, J., Dornhöfer, R., Eiser, A. and Hatz, W., "The New 2.0L TFSI with the Audi Valvelift System for the Audi A4 - The Next Generation of the Audi TFSI Technology", $17^{\text {th }}$ Aachen Colloquium, pp. 1067-1089, Aachen, Germany, $6^{\text {th }}-8^{\text {th }}$ October, 2008.
20. Copeland, C., Martinez-Botas, F., Turner, J.W.G., Pearson, R., Luard, N., Carey, C., Richardson, S., di Martino, P. and Chobola, P., "Boost System Selection for a Heavily Downsized Spark Ignition Prototype Engine", 10th International Conference on Turbochargers and Turbocharging, London, UK, $15^{\text {th }}-16^{\text {th }}$ May, 2012.

21. Robson, G., "Rallying - The Four-Wheel Drive Revolution", G T Foulis \& Co Ltd, $2^{\text {nd }}$ Ed., $1^{\text {st }}$ September, 1988, ISBN 0854297235.

22. Turner, J., Pearson, R., Curtis, R., and Holland, B., "Improving Fuel Economy in a Turbocharged DISI Engine Already Employing Integrated Exhaust Manifold Technology and Variable Valve Timing," SAE Technical Paper 2008-01-2449, 2008, doi:10.4271/2008-01-2449.

23. Lewis, A., Akehurst, S., Turner, J., Patel, R. et al., "Observations on the Measurement and Performance Impact of Catalyzed vs. NonCatalyzed EGR on a Heavily Downsized DISI Engine," SAE Int. J. Engines 7(1):458-467, 2014, doi:10.4271/2014-01-1196.

24. Remmert, S., Cracknell, R., Head, R., Schuetze, A. et al., "Octane Response in a Downsized, Highly Boosted Direct Injection Spark Ignition Engine," SAE Int. J. Fuels Lubr. 7(1):in press, 2014, doi:10.4271/2014-01-1397.

25. Dahnz, C., Han, K., Spicher, U., Magar, M. et al., "Investigations on Pre-lgnition in Highly Supercharged SI Engines," SAE Int. J. Engines 3(1):214-224, 2010, doi:10.4271/2010-01-0355.

26. Zahdeh, A., Rothenberger, P., Nguyen, W., Anbarasu, M. et al., "Fundamental Approach to Investigate Pre-Ignition in Boosted SI Engines," SAE Int. J. Engines 4(1):246-273, 2011, doi:10.4271/2011-01-0340.

27. Palaveev, S., Magar, M., Kubach, H., Schiessl, R. et al., "Premature Flame Initiation in a Turbocharged DISI Engine Numerical and Experimental Investigations," SAE Int. J. Engines 6(1):54-66, 2013, doi:10.4271/2013-01-0252.

28. Turner, J.W.G., Pearson, R.J., Milovanovic, N. and Taitt, D., "Extending the knock limit of a turbocharged gasoline engine via turboexpansion", $8^{\text {th }}$ Institution of Mechanical Engineers Conference on Turbochargers and Turbocharging, London, UK, May 2006.

29. Turner, J.W.G., "Interactions Between Charge Conditioning, Knock and Spark-Ignition Engine Architecture", Ph.D. Thesis, Loughborough University, Loughborough, UK, April 2011.

30. Taylor, J., Fraser, N., and Wieske, P., "Water Cooled Exhaust Manifold and Full Load EGR Technology Applied to a Downsized Direct Injection Spark Ignition Engine," SAE Int. J. Engines 3(1):225-240, 2010, doi:10.4271/2010-01-0356.

31. Smith, P. and Cheng, W., "Assessing the Loss Mechanisms Associated with Engine Downsizing, Boosting and Compression Ratio Change," SAE Technical Paper 2013-01-0929, 2013, doi:10.4271/2013-01-0929.

32. Hart, M., Gindele, J., Ramsteiner, Th., Thater, G., Tschamon, B., Karres, M., Keiner, B. and Fischer J., "The New High-performance 4-cylinder Engine with Turbocharging from AMG", $34^{\text {th }}$ International Vienna Motor Symposium, Vienna, Austria, 25 th $-26^{\text {th }}$ April, 2013.

33. Kuhlbach, K., Brinkmann, F., Bartsch, G., Weber, C., Do, G. and Jeckel, D., "Parallel sequential twin turbo boosting system applied to a 1.6 I DI gasoline engine", paper number 108, $18^{\text {th }}$ Supercharging Conference, Dresden, Germany, $12^{\text {th }}-13^{\text {th }}$ September, 2013.

34. Kuhlbach, K., Brinkmann, F., Werner, J., Kiener, T. and Becker, M., "Innovative Two-Stage Turbocharging System with Cooled Regulating Valve for Gasoline Engines", $22^{\text {nd }}$ Aachen Colloquium, pp. 951-974, Aachen, Germany, $8^{\text {th }}-9^{\text {th }}$ October, 2013.

35. Ardey, N., Wichtl, R., Steinmayr, T., Kaufmann, M., Hiemesch, D. and Stütz, W., "The All New BMW Top Diesel Engines", $33^{\text {rd }}$ International Vienna Motor Symposium, Book 1, pp. 111-136, Vienna, Austria, $26^{\text {th }}-27^{\text {th }}$ April, 2012.

\section{CONTACT INFORMATION}

Dr James Turner

SI Engine Research and Technology Leader

Jaguar Land Rover Powertrain Research

Abbey Road, Whitley, Coventry, CV3 4LF, UK

jturner1@jaguarlandrover.com 


\section{ACKNOWLEDGMENTS}

All of the partners express their sincere gratitude to the UK Technology Strategy Board for funding this exciting, challenging and successful engine technology project. The enthusiasm and support of the TSB Monitoring Officer for the project, Dave Ketcher, has been much appreciated throughout.

The technician who built these very complex engines was Carl Jenson, and his work in assembling them is much appreciated. The reliability demonstrated during testing is testament to the care with which this was done.

Finally, many talented people have contributed to the success of the project. Chris Carey was the original project leader within JLR and has since moved to another role within the company; he was responsible for maintaining that all of the project partners kept to a clear direction at the beginning. Others have moved from their original employers during Ultraboost but they still contributed to the project technically and therefore would probably have been co-authors of this paper. Consequently they are acknowledged with thanks here: Csaba Salamon and Malcolm Sandford (both ex-JLR), Richard Pearson, Nick Luard and Clive Card (all ex-Lotus), Steve Anstey (ex-GE Precision) and Bob Head (ex-Shell).

\section{DEFINITIONS/ABBREVIATIONS}

atdc - After top dead centre

BMEP - Brake mean effective pressure

CAHU - Combustion air handling unit

Cl - Compression ignition

CPS - Cam profile switching

CR - Compression ratio

CFD - Computational fluid dynamics

DCVCP - Dual continuously-variable camshaft phasing

DEP - Divided Exhaust Period

DF - Downsizing factor

DI - Direct injection

\author{
DISI - Direct-injection spark-ignition \\ EAT - Exhaust after treatment \\ EBP - Exhaust back pressure \\ ECU - Engine control unit \\ EGR - Exhaust gas recirculation \\ EMS - Engine management system \\ EVC - Exhaust valve closing \\ FMEP - Friction mean effective pressure \\ HTC - Heat transfer coefficient \\ IBC - Individual bulk container \\ IEM - Integrated exhaust manifold \\ IMEP - Indicated mean effective pressure \\ JLR - Jaguar Land Rover \\ KLSA - Knock-limited spark advance \\ LSPI - Low-speed preignition \\ mpUSg - Miles per US gallon \\ MY - Model year \\ NA - Naturally-aspirated \\ NEDC - New European Drive Cycle \\ $\bar{p}_{\text {brake - Brake mean effective pressure }}$ \\ PCP - Peak cylinder pressure \\ PFI - Port fuel injection \\ $\bar{p}_{\text {ind }}$ - Gross indicated mean effective pressure \\ r - Compression ratio \\ $\mathbf{V}_{\text {Swept }}$ - Swept volume \\ SI - Spark ignition \\ TDC - Top dead centre \\ TIT - Turbine inlet temperature \\ UB - Ultraboost (or Ultra Boost for Economy) \\ VEMB - Variable Exhaust-Modulated Boost \\ WCEM - Water-cooled exhaust manifold \\ WLTC - World Light-duty Test Cycle \\ $\boldsymbol{\eta}_{\text {mech }}$ - Mechanical efficiency \\ $\boldsymbol{\eta}_{\text {Otto }}$ - Otto air standard cycle efficiency \\ $\lambda$ - Relative air-fuel ratio
}




\section{APPENDIX}

\section{APPENDIX: FEDERAL CYCLE FUEL ECONOMY BENEFITS}

In this paper the results for the Federal test cycles have been presented in miles per US gallon (mpUSg), since the label figure on vehicles sold in North America would be presented in this way. It should be noted that the target set for this project was to reduce the NEDC cycle $\mathrm{CO}_{2}$ emissions by $35 \%$ and as the amount of $\mathrm{CO}_{2}$ produced is proportional to the amount of fuel burned, it is clear that the percentage improvement in fuel consumption is equal to the improvement in $\mathrm{CO}_{2}$. Therefore the fuel consumption (in litres per 100 kilometres) improvement target was also 35\%. At first glance the simulated improvements attributed to the engine step on the FTP-75 and the Metro Highway cycles look very impressive due to their high magnitude; however this can lead to misinterpretation of the results. As the FTP-75 cycle is more aggressive than the NEDC it is understood that the engine is typically working harder on this cycle, and it has been shown that the greatest benefits from downsizing typically occur at light load. Therefore it is expected that the fuel consumption benefit due to the engine alone on a more aggressive cycle would be lower than on a lighter load cycle. In order to assess how the benefit from the engine alone on the Federal cycles relates to that of the NEDC, they must be put into a unit where there is a linear relationship with the quantity of fuel saved (e.g., litres per 100 kilometres). The conversion mechanism from miles per US gallon to litres per 100 kilometres is shown in Equation A1.

$$
l / 100 \mathrm{~km}=\frac{3.79 \times 100}{1.609 \times \mathrm{mpUSg}}
$$

Once this conversion factor had been applied to the fuel economy result after each improvement step was applied (vehicle, vehicle plus stop-start and vehicle plus stop-start plus UB200), the fuel economy benefits and fuel consumption improvements could be assessed and attributed to each individual component by subtraction between steps.

The results from the FTP-75, Metro Highway and combined cycles in terms of both percentage increases in miles per US gallon and percentage reductions in litres per 100 kilometres are given in Tables A1 and $\underline{\text { A2}}$, respectively. Table A3 reproduces the NEDC $\mathrm{CO}_{2}$ improvements for reference.

Table A1. Federal cycle fuel consumption improvements in terms of miles per US gallon

\begin{tabular}{|c|c|c|c|}
\hline & $\begin{array}{c}\text { FTP-75 } \\
\text { mpUSg } \\
\text { Delta (\%) }\end{array}$ & $\begin{array}{c}\text { Metro } \\
\text { Highway } \\
\text { mpUSg } \\
\text { Delta (\%) }\end{array}$ & $\begin{array}{c}\text { Combined } \\
\text { mpUSg } \\
\operatorname{Delta}(\%)\end{array}$ \\
\hline $\begin{array}{c}2013 \mathrm{MY} \\
\text { Range Rover } \\
\text { with AJ133 }\end{array}$ & 11.3 & 7.8 & 10.1 \\
\hline \multicolumn{4}{|l|}{ NA V8 } \\
\hline Stop-start & 8.2 & 0.0 & 5.2 \\
\hline UB200 & 35.4 & 21.7 & 30.1 \\
\hline Total & 54.9 & 29.5 & 45.4 \\
\hline
\end{tabular}

Table A2. Federal cycle fuel consumption improvements in terms of litres per 100 kilometres

\begin{tabular}{|c|c|c|c|}
\hline & $\begin{array}{c}\text { FTP-75 } \\
\text { mpUSg } \\
\text { Delta (\%) }\end{array}$ & $\begin{array}{c}\text { Metro } \\
\text { Highway } \\
\text { mpUSg } \\
\text { Delta (\%) } \\
\end{array}$ & $\begin{array}{c}\text { Combined } \\
\text { mpUSg } \\
\text { Delta }(\%) \\
\end{array}$ \\
\hline $\begin{array}{l}2013 \text { MY } \\
\text { Range Rover } \\
\text { with AJ133 } \\
\text { NA V8 }\end{array}$ & 10.1 & 7.3 & 9.2 \\
\hline Stop-start & 6.2 & 0.0 & 4.1 \\
\hline UB200 & 19.1 & 15.5 & 17.9 \\
\hline Total & 35.4 & 22.8 & 31.2 \\
\hline
\end{tabular}


Table A3. NEDC fuel consumption improvements in $\mathrm{CO}_{2}$ in terms of grams per kilometre (for reference)

\begin{tabular}{|l|c|}
\cline { 2 - 2 } \multicolumn{1}{c|}{} & \multicolumn{1}{c|}{$\begin{array}{c}\text { NEDC } \\
\text { CO Delta } \\
\text { (\%) }\end{array}$} \\
\hline $\begin{array}{l}\text { 2013 MY } \\
\text { Range Rover } \\
\text { with AJ133 } \\
\text { NA V8 }\end{array}$ & 8.3 \\
\hline Stop-start & 7.6 \\
\hline UB200 & 21.0 \\
\hline Total & $\mathbf{3 6 . 9}$ \\
\hline
\end{tabular}

It can be seen from Table A2 that the improvements from the engine alone align with the expectation that the fuel consumption benefit would be lower on a higher load cycle (as the engine benefit on the FTP-75 of $19.1 \%$ is lower than the $21.0 \%$ on the NEDC). What can also be seen from these results is the increased benefit from the vehicle on the more aggressive cycle (due to the reduced inertia and aerodynamic drag of the MY 2013 vehicle versus the MY 2010 baseline for the project).

It should also be noted that the improvement values in terms of miles per US gallon are dependent on the order in which the technologies are applied due to the non-linearity of fuel economy with fuel consumption (see Figure A1: the percentage increase in fuel economy for a $5 \%$ decrease in fuel consumption is dependent on how many fuel consumption reducing technologies have already been applied). Therefore these values for percentage increase in fuel economy for each individual technology are only applicable to this specific case (when these technologies are implemented in that specific order). However, the values for fuel consumption reduction are applicable to each technology whether alone or grouped.

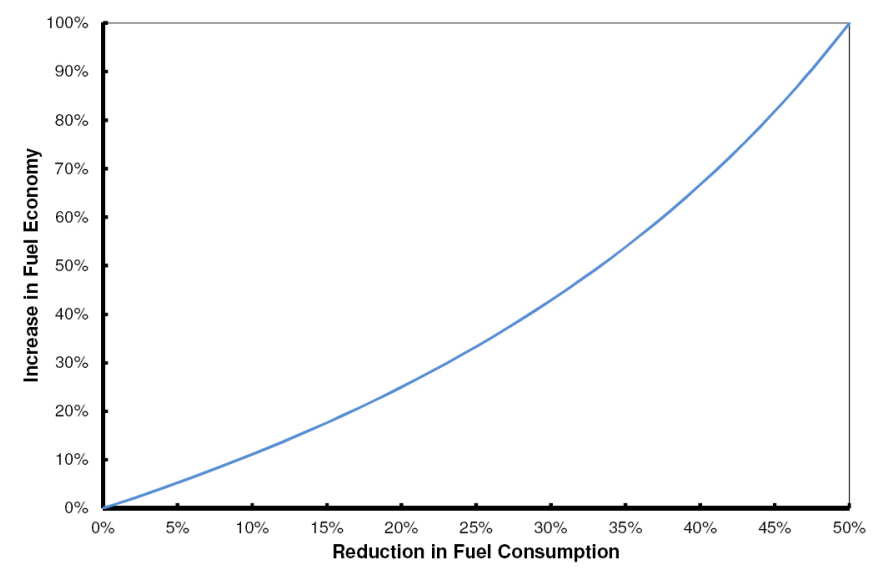

Fig. A1. Relationship between fuel consumption and fuel economy (reduction in fuel consumption in terms of fuel usage per unit distance and increase in fuel economy in terms of distance per unit fuel usage)

All rights reserved. No part of this publication may be reproduced, stored in a retrieval system, or transmitted, in any form or by any means, electronic, mechanical, photocopying, recording, or otherwise, without the prior written permission of SAE International. 